\title{
Temperature Shocks and Economic Growth: Evidence from the Last Half Century
}

\author{
Melissa Dell \\ MIT \\ Benjamin F. Jones \\ Northwestern University and NBER \\ Benjamin A. Olken \\ MIT and NBER
}

August 2011

\begin{abstract}
This paper uses historical fluctuations in temperature within countries to identify its effects on aggregate economic outcomes. We find three primary results. First, higher temperatures substantially reduce economic growth in poor countries. Second, higher temperatures appear to reduce growth rates, not just the level of output. Third, higher temperatures have wide-ranging effects, reducing agricultural output, industrial output, and political stability. These findings inform debates over climate's role in economic development and suggest the possibility of substantial negative impacts of higher temperatures on poor countries.
\end{abstract}

We thank Daron Acemoglu, Steven Davis, Esther Duflo, Douglas Gollin, Michael Greenstone, Jonathan Gruber, Seema Jayachandran, Charles Jones, Peter Klenow, Ross McKitrick, William Nordhaus, Elias Papaioannou, Fabrizio Perri, Richard Tol, Carl Wunsch, four anonymous referees, and numerous seminar participants for helpful comments and suggestions. Contact emails: mdell@mit.edu; bjones@kellogg.northwestern.edu; bolken@mit.edu. 


\section{Introduction}

At least since Montesquieu's The Spirit of Laws (1750), which argued that an "excess of heat" made men "slothful and dispirited", it has been debated whether temperature is - or is not central to understanding economic development. In this paper, we use historical fluctuations in temperature within countries to identify its effects on aggregate economic outcomes. We use this approach to inform old debates about the role of temperature in economic development and new debates about possible impacts of future warming.

The relationship between temperature and aggregate economic activity has traditionally been quantified using two approaches. One approach, emphasized in the growth and development literatures, has examined the relationship between average temperature and aggregate economic variables in cross-sections of countries (e.g. Sachs and Warner 1997; Gallup, Sachs, and Mellinger 1998; Nordhaus 2006). In contemporary data, it is well known that hot countries tend to be poor, with national income falling $8.5 \%$ per degree Celsius in the world cross-section (Dell et al. 2009). However, many argue that this correlation is driven by spurious associations of temperature with national characteristics such as institutional quality (e.g., Acemoglu, Johnson, and Robinson 2002; Rodrik, Subramanian, and Trebbi 2004).

The second approach relies on micro-evidence to quantify various climatic effects and then aggregates these to produce a net effect on national income. This approach is embedded within Integrated Assessment Models (IAM), which are utilized extensively in the climate change literature to model climate-economy interactions and form the basis of many policy recommendations regarding greenhouse gas emissions. A fundamental challenge for this approach is complexity: the set of candidate mechanisms through which temperature may influence economic outcomes is large and, even if each mechanism could be enumerated and its operation understood, specifying how they interact and aggregate poses substantial difficulties. The climate literature, at the micro level, suggests a wide array of potential temperature effects, including influences on agricultural productivity, mortality, physical performance, cognitive performance, crime, and social unrest, among other outcomes, many of which do not feature in current implementations of the enumerative models. ${ }^{1}$

\footnotetext{
${ }^{1}$ On agriculture, see, e.g., Adams et al. 1990, Mendelsohn et al. 2001, Schlenker and Roberts 2006, Deschenes and Greenstone 2007, and Guiteras 2007. On health, see, e.g. Curriero et al. 2002, Deschenes and Moretti 2007, Deschenes and Greenstone 2007, Gallup and Sachs 2001, and Sachs and Malaney 2002. On labor productivity, see,
} 
This paper takes an alternative approach. We first construct temperature and precipitation data for each country and year in the world from 1950 to 2003 and combine this dataset with data on aggregate output. We then examine the historical relationship between changes in a country's temperature and precipitation and changes in its economic performance. Our main identification strategy uses year-to-year fluctuations in temperature and precipitation to identify their effects. ${ }^{2,3}$ By examining aggregate outcomes directly, we avoid relying on a priori assumptions about what mechanisms to include and how they might operate, interact, and aggregate. By utilizing fluctuations in temperature, we isolate its effects from time-invariant country characteristics. Our approach also allows more nuanced insights: beyond investigating the magnitude and locus of any effects, we can use the panel's distributed lag structure to inform whether temperature impacts national growth rates or simply the level of income.

We find three primary results. First, our estimates show large, negative effects of higher temperatures on growth, but only in poor countries. In poorer countries, we estimate that a $1^{\circ} \mathrm{C}$ rise in temperature in a given year reduced economic growth in that year by about 1.3 percentage points. In rich countries, changes in temperature do not have a robust, discernable effect on

e.g., Huntington 1915, Meese et al. 1982, and Graff Zivin and Neidell (2010). On crime and social unrest, see, e.g. Field 1992, Jacob et al. 2007, and Miguel et al. 2004. Many other possible climate-economy channels are discussed in the Intergovernmental Panel on Climate Change $4^{\text {th }}$ Assessment Report (IPCC 2007). Main users of IAM models acknowledge that the aggregate estimates require numerous, difficult modeling decisions. For example, the Stern report on the economics of climate change writes: "Making such estimates is a formidable task in many ways... with the result that such models must make drastic, often heroic, simplifications along all stages of the climate-change chain. What is more, large uncertainties are associated with each element in the cycle. Nevertheless, the IAMs remain the best tool available for estimating aggregate quantitative global costs and risks of climate change" (Stern et al. 2007, p. 145).

${ }^{2}$ The use of annual variation to estimate the impact of climate change was pioneered by Schlenker and Roberts (2006) and Deschenes and Greenstone (2007), who use annual county-level U.S. data to estimate the impact of weather on U.S. agricultural output. Several authors have also used higher frequency data, focusing on the GDP effect of rainfall in Africa as an instrument for conflict (Miguel et al 2004) and to explain the African growth tragedy (Barrios et al. 2010).

${ }^{3}$ By convention, an annual realization of temperature and precipitation is termed "weather" while the word "climate" refers to the long-run distribution of temperature and precipitation. This paper thus emphasizes weather variation, although Section 5 considers historical variation at longer time scales and along a path where the world is becoming warmer. 
growth. Changes in precipitation have relatively mild effects on national growth in both rich and poor countries. ${ }^{4}$ We find broadly consistent results across a wide range of alternative specifications.

Second, to interpret these effects, one can distinguish two potential ways temperature could affect economic activity: 1) influencing the level of output, for example by affecting agricultural yields, or 2) influencing an economy's ability to grow, for example by affecting investments or institutions that influence productivity growth. By looking at multiple lags of temperature, we can examine whether shocks appear to have temporary or persistent impacts on economic output, and thus whether temperature has level or growth effects (or both). Our results suggest that higher temperatures may reduce the growth rate in poor countries, not simply the level of output. Since even small growth effects have large consequences over time, these growth effects - if they persist in the medium run - would imply large impacts of warming.

Third, we find evidence that temperature affects numerous dimensions of poor countries' economies in ways consistent with growth effects. While agricultural output contractions appear to be part of the story, we also find adverse effects of hot years on industrial output. Moreover, higher temperatures lead to political instability in poor countries, as evidenced by irregular changes in national leaders, and this political instability could plausibly reduce growth rates. ${ }^{5}$ These effects sit outside the primarily agricultural focus of much economic research on climate change and underscore the challenges in building aggregate estimates of climate impacts from a narrow set of channels. They are consistent with other recent work that suggests that temperature can have broad impacts outside of agriculture (Hsiang 2010). These effects may also help explain how temperature might affect growth rates in poor countries, not simply the level of output.

These results are identified using short-run fluctuations in temperature and precipitation, whereas the long-run effects of climate may be different. For example, in the long run, countries may adapt to a particular temperature, mitigating the short-run economic impacts that we

\footnotetext{
${ }^{4}$ Precipitation does show positive effects on agricultural output in poor countries, as discussed in Section 4.

${ }^{5}$ The idea that climate shocks can affect political institutions is consistent with Brückner and Ciccone (2011), which shows that negative rainfall shocks lead to an increased probability of democratization in Sub-Saharan Africa. Burke and Leigh (2010) also find that output contractions associated with weather shocks affect the timing of democratic change.
} 
observe. This type of adaptation may explain why our estimates of short-run economic impacts of temperature shocks are larger than what the overall cross-sectional relationship between temperature and income across the world would imply (see Section 6). Alternatively, sustained climatic changes may have additional long-run effects on dimensions such as water tables, soil quality, and health, producing larger impacts (e.g., Meehl et al. 2004). ${ }^{6}$

Although our approach cannot fully overcome these challenges, we can make some headway in exploring potential impacts of shifts in climate by examining medium-term temperature shifts within countries. Mean global land temperatures have risen nearly $1{ }^{\circ} \mathrm{C}$ since 1970 (Brohan et al. 2006), but countries have not warmed equally. We therefore examine whether those countries that experienced the largest climatic shifts between early and late periods in our sample had the largest shifts in their growth rates. Though this approach has less statistical power than using annual variation, the estimated effects of increased temperature over 10 or 15-year time horizons are similar to our annual panel estimates, showing substantial negative effects in poor countries. The decline in statistical precision with these medium-term results means that they should be interpreted with more caution than the annual panel data results, but the fact that they appear consistent is suggestive that the effects may persist at least over the medium term.

Our evidence suggests specific directions in which IAMs could be modified to better match the historical evidence. The two key distinctions between our evidence and the assumptions in most IAM models are that a) our estimates show striking differences between rich and poor countries and b) our estimates explicitly allow growth effects of higher temperatures (for example, on TFP growth), not just level effects. Incorporating these effects in aggregate climate-economy models would help them predict long-run output paths that are consistent with the evidence in the short and medium run.

Our results also inform the older debate over temperature's role in economic development. Climatic theories of development have a long history, with prominent examples dating to Huntington (1915), Montesquieu (1750), and even to Ibn Khaldun's $14^{\text {th }}$ Century Muqaddimah (Gates 1967). Yet even with contemporary analysis there remains substantial

\footnotetext{
${ }^{6}$ In the context of future global climate change, other factors such as changing sea levels, increasing frequency of natural disasters, and issues of biodiversity may create additional costs not captured here (IPCC 2007; Nicholls and Leatherman 1995)
} 
debate over temperature's aggregate effects (e.g., Acemoglu et al. 2002, Sachs 2003). Our estimates identify a substantial, contemporary causal effect of temperature on the development process, providing explicit evidence that temperature affects not only numerous sub-components in an economy, but aggregates into substantial impacts on national output.

The remainder of the paper is organized as follows. Section 2 introduces the data and provides descriptive statistics. Section 3 describes the estimation strategy, presents the main results, and considers a number of robustness checks. Section 4 considers channels that may link temperature change to national output. Section 5 estimates the effects of longer-run temperature shifts. Section 6 relates the historical panel estimates to the cross-sectional relationship between temperature and income, and discusses some implications of the results for understanding potential economic effects of climate change. Section 7 concludes.

\section{Data and Descriptive Statistics}

\subsection{Data}

The historical weather data are taken from the Terrestrial Air Temperature and Precipitation: 1900-2006 Gridded Monthly Time Series, Version 1.01 (Matsuura and Willmott 2007). This data set provides worldwide (terrestrial) monthly mean temperature and precipitation data at $0.5 \times 0.5$ degree resolution (approximately $56 \mathrm{~km} \times 56 \mathrm{~km}$ at the equator). Values are interpolated for each grid node from an average of 20 different weather stations, with corrections for elevation.

We use geospatial software to aggregate the weather data to the country-year level. Our main specifications use population-weighted average temperature and precipitation, where the weights are constructed from 1990 population data at 30 arc second resolution (approximately $1 \mathrm{~km}$ at the equator) from the Global Rural-Urban Mapping Project (Balk et al. 2004). We also consider averaging based on geographic area, which produces broadly similar weather variables for most countries. ${ }^{7}$ Appendix I presents additional details about the temperature and precipitation data.

For economic data, we primarily use the World Development Indicators (World Bank

\footnotetext{
${ }^{7}$ Countries where the weighting scheme makes a substantial difference are those with large, sparsely populated areas with unusual climates: Russia (Siberia), Canada (the arctic and sub-arctic areas), the United States (Alaska), and Australia (central Australia).
} 
2007). We focus on the panel of 125 countries with at least 20 years of GDP data in the World Development Indicators, and consider other samples as robustness checks. We also consider economic growth data from the Penn World Tables Version 6.2 (Heston et al. 2006) as a robustness check and find very similar results. We use the World Development Indicators as our primary dataset given recent concerns with high frequency PWT data (Johnson et al 2009).

\subsection{Descriptive statistics}

Figure 1 summarizes temperature (left graph) and precipitation (right graph) data for each country in the sample, plotted against log per-capita PPP GDP in the year 2000. For each country, the circle symbols represent the mean levels of temperature and precipitation in the first decade of our sample (1950-1959), the plus symbols represent the mean levels in the last decade of our sample (1996-2005), and the gray lines indicate the range of annual mean levels we observe for that country. On average, our data show that the world has become about $1{ }^{\circ} \mathrm{C}$ warmer between the early and late parts of our sample. The warming trend, which is concentrated since the 1970s, is well-documented (e.g. Brohan et al. 2006).

The left panel of Figure 1 shows the tremendous temperature variation across countries: the hottest country in the world is Mauritania, with an average population-weighted temperature of $28.4^{\circ} \mathrm{C}$, and the coldest is Mongolia, with an average population-weighted temperature of $-1.77^{\circ} \mathrm{C}$. Figure 1 also shows the strong relationship between temperature and per-capita income, with hot countries tending to be poor and cold countries rich. This relationship has been known since at least the $18^{\text {th }}$ century (Montesquieu 1750) and has been further established using subnational data (Nordhaus 2006). The exceptions to this rule fall into two main groups: oil states of the Middle East, such as Qatar and Kuwait, which are hot and wealthy, and Communist / postCommunist states, Mongolia and North Korea, which are cold and poor. On average, a simple cross-section regression in the year 2000 shows that a $1{ }^{\circ} \mathrm{C}$ increase in average temperature predicts a fall in per-capita income by $0.085 \log$ points (i.e. about 8 percent).

Looking at variability within countries, we see fluctuations in annual mean temperatures, with the difference between the maximum and minimum annual mean temperature within a country averaging $2.2^{\circ} \mathrm{C}$ in our baseline sample. ${ }^{8}$ Thus, the max-min variation within countries is more than twice the average increase in temperature observed over the period and reasonably

\footnotetext{
${ }^{8}$ This max-min difference in annual means within countries ranges between 1.3 and $3.4{ }^{\circ} \mathrm{C}$ for 95 percent of countries in our baseline sample.
} 
similar to estimated global temperature increases expected to occur over the next century. Figure 1 further shows that, while there tend to be larger temperature fluctuations in cooler countries, the upward trend in temperature has occurred globally with similar magnitude in both hot and cold countries.

Examining the data on precipitation in the right panel of Figure 1 shows substantial annual variability in precipitation in all but the very driest countries. However, there is no clear relationship between the level of precipitation and the level of per-capita income in 2000 .

To examine the variability further, Table 1 documents the extent of temperature and precipitation fluctuations within countries. While the average difference (across all countries) between the hottest and coldest year is $2.2^{\circ} \mathrm{C}$ (Figure 1), a country's temperature deviates more than $1{ }^{\circ} \mathrm{C}$ from the country mean approximately once every fifteen years. Precipitation is more volatile, with deviations from mean rainfall of about 400-500 $\mathrm{mm}$ appearing once every fifteen years. When common global or region-specific year fixed effects are removed, these deviations become somewhat more modest.

\section{The Effect of Temperature Fluctuations on Economic Activity}

In this section we develop the empirical framework for the analysis of temperature shocks, present our main results, and consider a variety of robustness checks.

\subsection{Empirical framework}

Our empirical framework follows the derivation in Bond et al. (2010). To fix ideas, consider the following simple economy: ${ }^{9}$

$$
\begin{aligned}
& Y_{i t}=e^{\beta T_{i t}} A_{i t} L_{i t} \\
& \Delta A_{i t} / A_{i t}=g_{i}+\gamma T_{i t}
\end{aligned}
$$

where $Y$ is aggregate output, $L$ measures population, $A$ measures labor productivity, and $T$ measures weather. Equation (1) captures the level effect of weather on production; e.g. the effect of current temperature on crop yields. Equation (2) captures the growth effect of weather; e.g. the effect of temperature on features such as institutions that influence productivity growth.

Taking logs in the production function and differencing with respect to time, we have the

\footnotetext{
${ }^{9}$ We focus here on this simple production model. Appendix II extends the reasoning developed here to more general dynamic panel models that incorporate richer lag structures and lagged dependent variables.
} 
dynamic growth equation

$$
g_{i t}=g_{i}+(\beta+\gamma) T_{i t}-\beta T_{i t-1}
$$

where $g_{i t}$ is the growth rate of per-capita output. The "level effects" of weather shocks on output, which come from equation (1), appear through $\beta$. The "growth effects" of weather shocks, which come from equation (2), appear through $\gamma .{ }^{10}$

The growth equation in (3) allows separate identification of level effects and growth effects through the examination of transitory weather shocks. In particular, both effects influence the growth rate in the initial period of the shock. The difference is that the level effect eventually reverses itself as the weather returns to its prior state. For example, a temperature shock may reduce agricultural yields, but once temperature returns to its average value, agricultural yields bounce back. By contrast, the growth effect appears during the weather shock and is not reversed: a failure to innovate in one period leaves the country permanently further behind. The growth effect is identified in (3) as the summation of the temperature effects over time.

The above reasoning extends to models where temperature effects play out more slowly. ${ }^{11}$ With more general lag structures in (1) and (2), the growth effect is still identified by summing the lagged effects of the weather fluctuation. This standard distributed-lag result is demonstrated formally in Appendix II.

To estimate these effects, we run panel regressions of the form

\footnotetext{
${ }^{10}$ Rather than first-differencing (1), one could integrate (2), producing a fully-specified equation in the log level of output. However, as Bond et al. (2010) notes, this creates non-stationarity in both output levels (on the left-hand side) and accumulable factors (on the right-hand side). To avoid relying on cointegration assumptions for identification, Bond et al. recommend first-differencing. Appendix II presents Monte Carlo results, which show that the first-differencing approach is very effective at correctly identifying both level effects $(\beta)$ and growth effects $(\gamma)$, whereas the integrated model with the log level of output as the dependent variable correctly identifies level effects $(\beta)$ but does a poor job identifying growth effects $(\gamma)$. Given these results, we focus on the model with growth as the dependent variable as in equation (3).

${ }^{11}$ For example, low temperatures in the latter part of one year could affect harvests the next year - which would generate a lagged level effect. Alternatively, a permanent shock to productivity could influence subsequent capital accumulation as the capital stock adjusted to its new steady state - which would generate a lagged growth effect. The key distinction is that, as in equation (3), level effects eventually generate equal and opposite responses through further lags, whereas growth effects do not. See Appendix II.
} 


$$
g_{i t}=\theta_{i}+\theta_{r t}+\sum_{j=0}^{L} \rho_{j} T_{i t-j}+\varepsilon_{i t}
$$

where $\theta_{i}$ are country fixed effects, $\theta_{r t}$ are time fixed effects (interacted separately with region dummies and a poor country dummy in our main specifications), $\varepsilon_{i t}$ is an error term clustered simultaneously by country and region-year (following the two-way clustering of Cameron et al. 2011 ), and $T_{i t}$ is a vector of annual average temperature and precipitation with up to $L$ lags included. ${ }^{12}$ In addition, we also consider variations of (4) that include interactions between weather variables and country characteristics. We have verified using Monte Carlo analysis that the specification in (4) produces unbiased estimates of both growth and level effects given the properties of our data. (See Appendix II for more details.)

We begin by estimating (4) with no lags, focusing on the null hypothesis that temperature does not affect growth:

$$
H_{0}(L=0): \rho_{0}=0
$$

A failure to reject this hypothesis would indicate an absence of both level and growth effects. In subsequent regressions with lags, following the conventions in the distributed-lag literature (see Greene 2000), we separately test the immediate effect of temperature:

$$
H_{0}^{1}(L>0): \rho_{0}=0
$$

and the cumulated effect of temperature:

$$
H_{0}^{2}(L>0): \sum_{j=0}^{L} \rho_{j}=0
$$

The summation of the lag coefficients corresponds to the parameter $\gamma$, the growth effect, in the simple model above, as well as a more general concept of growth effects in models with longer lag structures, as demonstrated in Appendix II. Appendix II also discusses generalizations of the empirical model and tests following Bond et al. (2010) that allow for more general short-run dynamics. As discussed in the appendix, the results from the extended dynamic model are very similar to the results from the simpler model developed here.

\subsection{Panel results}

Table 2 examines the null hypothesis that temperature does not affect growth, either through level effects or growth effects. It presents results from estimating equation (4) with no

\footnotetext{
${ }^{12}$ The regions are Middle East/North Africa, Sub-Saharan Africa, Latin America and Caribbean, Western Europe and offshoots, Eastern Europe and Central Asia, and Asia and Pacific Islands. See the appendix for a full list of countries.
} 
lags (i.e., imposing $\rho_{j}=0$ for all $j>0$; models with lags are examined in the next subsection). Column (1) of Table 2 shows a negative but statistically insignificant relationship between temperature fluctuations and growth on average across all countries. In column (2), we interact temperature with a dummy for a country being "poor", defined as having below-median PPPadjusted per-capita GDP in the first year the country enters the dataset. The coefficient on the interaction between the "poor" dummy and temperature is negative and statistically significant, indicating substantial heterogeneity between poor and rich countries. ${ }^{13}$ As shown in the last row of the table (which reports the sum of the main effect of temperature and its interaction with the poor dummy), the net effect of a $1^{\circ} \mathrm{C}$ rise in temperature is to decrease growth rates in poor countries by -1.39 percentage points. Put another way, since the standard deviation of annual temperature once country fixed effects, region $\times$ year, and poor country $\times$ year fixed effects are removed is 0.50 degrees (see Table 1 for more detail), the estimates in Table 2 imply that a onestandard deviation increase in annual temperature is associated with a reduction in growth of about 0.69 percentage points.

The next column of Table 2 adds precipitation as a control variable, and shows that controlling for precipitation does not substantively affect the temperature estimates. Average annual precipitation itself shows relatively mild effects: an extra $100 \mathrm{~mm}$ of annual precipitation is associated with a 0.08 percentage point lower growth rate in rich countries and a statistically insignificant 0.07 percentage point higher growth rate in poor countries. In our data, global mean precipitation levels have fallen nearly $100 \mathrm{~mm}$ in the last 50 years, so a $100 \mathrm{~mm}$ variation in precipitation is on the same order historically as the $1^{\circ} \mathrm{C}$ rise in temperature. By this metric, the effects of mean precipitation typically appear a factor of 10 times smaller than the temperature effect in poor countries. ${ }^{14}$ Moreover, Table 4 below shows that the statistical significance of the

\footnotetext{
${ }^{13}$ We have also considered quintiles of initial per-capita income rather than a binary distinction. We find the largest negative effects of temperature on the bottom 2 quintiles of temperature, and especially on the lowest income quintile. Using an interaction with a linear initial log per-capita income variable produces similar results, although the linear specification implies positive effects of temperature in rich countries which do not appear with either the rich/poor dummy or using quintiles. (See online appendix.)

${ }^{14}$ As an alternative metric, the standard deviation of precipitation in Table 1 across the entire sample (after removing fixed effects) is about $25 \mathrm{~mm}$, so a one-standard increase in precipitation would increase growth in poor countries by a (statistically insignificant) 0.02 percentage points, or about $1 / 40$ the estimated effect of a one-standard deviation in temperature.
} 
precipitation effects in rich countries is sensitive to specification, suggesting that they should be interpreted with caution. $^{15}$

Poorer countries tend to be both hotter and more agricultural. In columns (4) and (5) we consider whether being "poor" proxies for these characteristics. Column (4) adds the interaction between temperature and "hot", defined as having above median temperature in the 1950s. The negative effect of temperature appears through being poor, not through being hot, with the poor coefficient remaining unchanged. ${ }^{16}$ Column (5) controls for the interaction between temperature and "agricultural", defined as having an above median agricultural GDP share in $1995 .{ }^{17}$ Once again, the negative effect of temperature appears through being poor. ${ }^{18}$ While it is impossible to definitively separate the impacts of poverty from those of the agriculture share or mean temperature (or the many other variables that are correlated with poverty), this evidence suggests that being poor usefully characterizes a locus of substantial negative temperature effects.

The point estimates in Table 2 tend to show that rich countries experience increased growth with a rise in temperature, but this result is not statistically significant, with t-statistics below 1.0 for all specifications except the last, which controls for agricultural intensity. Looking ahead to further results in the paper and the Appendices, which examine alternative analyses and

\footnotetext{
${ }^{15}$ In Section 4 below, precipitation is shown to have a more robust, positive effect on agricultural output in poor countries. These results on average precipitation also do not capture the impact of extreme precipitation events, such as extended droughts or flooding. However, Appendix Figure A3 suggests that the negative effects of precipitation in rich countries are driven by very large outlier events, suggesting that indeed floods may be important. Also, given the large heterogeneity in growing seasons between countries, we do not distinguish between rain in the growing, harvest, planting, or dry seasons as done, e.g., by Maccini and Yang (2009).

${ }^{16}$ In results not reported in the table, we have also experimented with different definitions of "hot," such as being above the $75^{\text {th }}$ or $90^{\text {th }}$ percentiles of the world average temperature distribution, as well a linear temperature variable. The results from these alternative specifications are qualitatively similar to the results presented in the table. See the online appendix.

${ }^{17}$ We use 1995 data for agricultural share because data coverage from earlier years is sparse. Using earlier data cuts sample sizes considerably but produces broadly similar results.

${ }^{18}$ As reported in the online appendix, regressions that control only for temperature fluctuations and their interaction with the agriculture share (i.e. not including interactions with national income) produce statistically insignificant effects for agriculture, further suggesting that poverty is the more informative characteristic. Furthermore, regressions that include linear interactions with initial income, temperature, and agriculture share (as opposed to binary dummies) continue to show that initial poverty is the relevant distinction.
} 
robustness checks for the panel specifications, data sources, and sample, the econometric findings tend to show this similar pattern - typically positive but rarely statistically significant temperature effects in rich countries.

\subsection{Models with lags}

The above results, using the simple model with no lags, reject the null hypothesis that temperature has no effect on growth in poor countries. This section considers more flexible models with up to 10 lags of temperature to better understand the dynamics of these temperature effects, nesting both the level and growth effects of temperature described in Section 3.1.

Table 3 presents results from estimating equation (4) with no lags, one lag, three lags, five lags, or ten lags of the weather variables. In columns (1) - (5), temperature and its lags are the only temperature and precipitation variables included. Columns (6) - (10) present results where precipitation and its lags are also included. All temperature and precipitation variables are interacted with poor and rich country dummies. The bottom two rows of each column present, separately, the cumulated effect of temperature for poor and rich countries, calculated by summing the respective temperature variable and its lags. In models with more than three lags, given space constraints, the table reports only the first three lags and the sum of all the lags. ${ }^{19}$

Table 3 shows that the cumulative effect of temperature in poor countries becomes more negative as more lags are included. With no lags, in columns (1) and (6), a one-time $1^{\circ} \mathrm{C}$ temperature increase in a poor country reduces growth by $1.35-1.39$ percentage points. With one lag included, the cumulative effect is a reduction of $0.98-1.10$ percentage points. The results are broadly consistent in magnitude and statistical significance as we add more lags, with a $1^{\circ} \mathrm{C}$ temperature increase producing a $1.04-1.28$ percentage point reduction in growth, with the only exception being that cumulative effect with 10 lags of temperature, when we also include 10 lags of precipitation (column 10), is 0.858 and is no longer statistically significant.

The individual lag coefficients show little evidence of a level effect of temperature on output. That is, the effects of above average temperature appear to persist in the medium-run, rather than being reversed. Recalling the empirical framework from Section 3.1, level effects are reversed when the temperature shock is reversed. In the model with one lag - i.e., columns (2) and (6) - a level effect would appear as equal and opposite coefficients on the immediate effect and the first lag. More generally, even if level effects occur with lags - i.e., if last year's

\footnotetext{
${ }^{19}$ The full set of lags for Table 3, Column 10 is reported in Appendix Table A34.
} 
temperature affects this year's harvest - level effects are eventually reversed once the shock disappears. Therefore, to the extent temperature effects are level effects, the cumulated sum of the temperature effect and all its lags should be zero. That the lags in Table 3 do not sum to zero suggests that the effects of temperature persist in the medium run; i.e., they look more like growth effects than level effects.

Of course, temperature effects may be mitigated beyond the 10-year horizon examined here. In Section 5, we consider an alternative empirical approach that examines longer-run historical relationships between changes in temperature and changes in growth. That analysis finds longer-run effects that are broadly consistent with these panel results but less statistically significant.

\subsection{Robustness}

This section considers a variety of robustness checks, summarized in Table 4. Numerous additional analyses are presented in the Appendix. We consider robustness to alternative panel specifications, samples and data sources, and further examine non-linear temperature effects.

\subsubsection{Panel specifications}

We find that the results are broadly consistent across a range of alternative panel specifications, particularly the results with no lags. In Table 4, Panel A reports the results from models with no lags, while Panels B and C report cumulative effects from models with five and ten lags respectively. ${ }^{20}$ To facilitate comparisons, the relevant results from Tables 2 and 3 are repeated in the first column of Table 4 . The results in column (2), which incorporate countryspecific trends as well as region $\times$ year and poor $\times$ year fixed effects, appear to be somewhat larger in magnitude than the baseline results, suggesting that the results are not being driven by secular time trends within countries. Column (3) shows that including country and region $\times$ year fixed effects only (i.e., dropping the poor $\times$ year fixed effects) produces similar estimated temperature effects in poor countries to the baseline results, though the results with 5 and 10 lags attenuate. Similar results also emerge in column (4), which use common global year fixed effects

\footnotetext{
${ }^{20}$ The results in Panel A correspond to column 3 of Table 2. Panels B and C correspond to columns 9 and 10 of Table 3. Results from models with one and three lags are qualitatively similar and are omitted to conserve space.
} 
instead of region $\times$ year fixed effects and also drop the poor $\times$ year fixed effects. ${ }^{21}$

As discussed in Appendix II and presented in Appendix Table A1, the results are robust to more general dynamic panel regression models that use various lag structures. As an additional specification check, Appendix Tables A37-38 report regressions that include one to ten leads of temperature. In no case are the leads significant, even when the contemporaneous temperature term is omitted. When controlling for leads, the contemporaneous and cumulated lag temperature effects remain of similar magnitude to those in the main results.

Finally, we have also investigated alternative formulations of the temperature and precipitation variables. First, we have considered using logs rather than levels of annual average temperature and precipitation. This specification strengthens the results. Second, we have constructed weather anomalies, normalizing annual temperature and precipitation by subtracting each country's mean and dividing by each country's standard deviation. This specification produces similarly-sized impacts although standard errors typically increase, suggesting a model based on absolute temperature differences may be more appropriate. These results are all available in the online appendix.

\subsubsection{Sample and data sources}

Since countries' growth data starts at different dates, Table 4 (column 5) repeats the main specification on a balanced sample where all countries are present in the sample for the entire period. $^{22}$ The point estimates are almost identical to the baseline results, although the standard errors in the 5 and 10 lag specifications increase, as one might expect given that we have reduced the amount of data in the model. Expanding the data to include countries with less than 20 years of data also continues to show substantial negative effects in poor countries (column 6), with little change from the baseline specification.

Table 4 column (7) reconsiders the main specification using growth data from the Penn World Tables rather than the Penn World Tables. The results are very similar, though the 10 lag

\footnotetext{
${ }^{21}$ We have also estimated a first differenced version of (4), i.e. $\Delta g_{i t}=\Delta \theta_{r t}+\sum_{j=0}^{L} \rho_{j} \Delta T_{i t-j}+\Delta \varepsilon_{i t}$. This produces very similar results for the 0 lag model, while the estimates become substantially more negative and more imprecise as we add additional lags. These results are available in the online appendix.

${ }^{22}$ Note that temperature and precipitation data is present over the entire period, so having different start dates for the growth data is not an issue for calculating the lags in the model, since we can always calculate the lags of the weather data even if the growth data is missing.
} 
result is now statistically significant. Column (8) uses temperature and precipitation data aggregated using area-weighting rather than population-weighting and shows similar effects, though the zero-lag effect for rich countries is now statistically significant. ${ }^{23}$ Splitting the sample into Sub-Saharan African countries (column 9) and all other countries (column 10), the model with zero lags shows that the negative impacts of temperature are especially pronounced in Sub-Saharan Africa, but are still negative and statistically significant elsewhere, and the difference between the Sub-Saharan Africa and non- Sub-Saharan Africa samples is not statistically significant. ${ }^{24}$ When we examine either the five or ten lag models, the negative point estimates are comparable in magnitude in both samples. ${ }^{25}$

National accounts are notoriously hard to measure, particularly in developing countries (Deaton and Heston 2010; Ciccone and Jarocinski 2010; Young 2009). To investigate the extent to which measurement problems in the data are driving the results, we have examined the impact of temperature on exports. Since exports from poor countries are reported by the importing countries, these data are much more accurately measured than national accounts data. As reported in Jones and Olken (2010), analyzing export growth data as recorded by the U.S. and other importing countries shows similarly large negative effects of increased temperature on poor countries' exports, but not on rich countries' exports. This finding indicates that the core panel finding is not driven by potentially low-quality national accounts data in poor countries.

Finally, we have investigated concerns that the temperature and precipitation data quality may be lower for poor countries, and concerns in particular that weather stations may enter or exit our sample in response to economic conditions. First, we have repeated our analysis of

\footnotetext{
${ }^{23}$ Weighting by rural population or urban population yields similar results to using total population weights; see the online appendix.

${ }^{24}$ Given the very small number (3) of rich countries in Sub-Saharan Africa, we group these together into a unified Sub-Saharan African sample.

${ }^{25}$ Our results do differ from Barrios et al. (2010), who in their investigation of rainfall in Sub-Saharan Africa include temperature as a control in one specification, finding no effects. Our specification differs from theirs on many dimensions; Barrios et al examine fewer countries and fewer years of data, use a different temperature variable, and use a somewhat different empirical specification.
} 
Africa with a number of alternative weather datasets. ${ }^{26}$ Results are broadly similar in all samples, although limited size for alternative data sets reduces the estimates' precision. Second, the GHCN dataset (the main underlying source for the Matsuura and Willmott (2007) data we use here) indicates whether a weather station is missing an observation in a given year. Using panel regression models, we find no relationship between economic conditions or political instability and the number of weather stations that are missing data in a given country and year. ${ }^{27}$

\subsubsection{Non-Linear Temperature Effects}

In our analysis, temperature enters linearly, whereas one might suspect that temperature has non-linear effects. ${ }^{28}$ To further investigate this possibility, beyond the interaction terms examined in Table 2, we examined more flexible aggregations of the sub-national temperature data. Using daily temperature and precipitation data available on a $1.0 \times 1.0$ degree grid (NCC 2005), we calculated the number of 'people-days' spent at each temperature and precipitation level throughout the year for each country. We then repeated the panel analysis above (e.g., equation (4) with no lags) allowing the temperature and precipitation effects to vary arbitrarily at different temperature and precipitation ranges. Unfortunately, we did not have sufficient power to tease out detailed effects of the distribution of days within different temperature ranges, given that our dependent variable is measured at the annual, country level. While the results are imprecise, the point estimates suggest that the impact of temperature on GDP is roughly linear, supporting the focus on annual averages (see online appendix).

We have also conducted additional analysis of nonlinear effects of the average temperature variable, finding little evidence for such non-linearities. First, we verified that both hot and cold deviations from the national temperature mean have effects of similar absolute

\footnotetext{
${ }^{26}$ These alternative datasets are the Global Precipitation Climatology Project, the National Center for Environment Prediction, and the UN Food and Agricultural Organization Climatic Data, which provide alternative precipitation series. See online appendix for analysis and further discussion.

${ }^{27}$ In particular, we run panel regressions relating the share of stations that are missing in a given country and year (the dependent variable) to economic growth and political instability measures (interacted with poor country dummies). These regressions show no effect of these economic and political variables on station reporting in poor countries. See the online appendix.

${ }^{28}$ For example, Deschenes and Greenstone (2007a, 2007b) find non-linear temperature effects for agriculture and mortality, and Schlenker, Hanemann, and Fisher (2006), Schlenker and Roberts (2006), and Schlenker and Roberts (2009) find important non-linear temperature effects for agriculture.
} 
magnitude on growth. Second, we found that temperature shocks do not affect poor countries differentially depending on whether the country is typically hot or cold, though the tiny number of cold poor countries prevents a definitive conclusion. ${ }^{29}$ Although our power to assess nonlinearities is limited given the few degrees of variation in temperature within each country, the evidence here does not show substantial nonlinearities.

\section{Channels}

The large and persistent effects of temperature shocks on aggregate output in poor countries suggest further investigation of the temperature-economy relationship. Many macroeconomic models of climatic effects emphasize a limited set of channels, especially agriculture, and income level effects, rather than effects on factor accumulation or other dimensions that could impact growth. The microeconomic literature, by contrast, considers broader dimensions of climatic effects, including physical and cognitive labor productivity, conflict, and health, all of which could have economy-wide implications. ${ }^{30}$ At the same time, the micro evidence often comes from local environments, usually in rich countries, which may or may not extend to national settings or to poor countries. In this section, we apply our panel methodology to explore whether the effects of temperature are primarily limited to agriculture, or whether temperature affects other important dimensions. Such analysis tests the narrow focus of mainstream aggregate climate-economy models and may also help inform our finding of growth effects in the distributed lag structure.

Note that these analyses are reduced-form, and therefore do not identify the possibly complex structural relationships between temperature, growth, and other outcomes. For example, higher temperature could lead directly to political instability by making a population more prone to riot (United States Riot Commission, 1968; Carlsmith and Anderson, 1979). Conversely higher temperatures could lower agriculture yields, with the resulting GDP reduction provoking political instability. Teasing out structural relationships between these many variables would require a number of ad hoc identifying assumptions and lies far beyond the scope of this single study. We focus instead on net effects, which we can identify clearly, to shed light on the breadth and type of potential channels through which temperature may affect aggregate output. The results, which show impacts not only on agriculture, but also on industrial output and political

\footnotetext{
${ }^{29}$ These results are presented in Appendix Table A39.

${ }^{30}$ Footnote 1 provides a brief summary of this very large literature.
} 
stability, emphasize temperature's broad influences and help inform our findings of growth effects.

\subsection{Agriculture, Industry, and Investment}

Table 5 examines the impact of temperature and precipitation on several components of GDP. Panel A begins with zero-lag models to test the null hypotheses of no effects of temperature. Columns (1) through (3) examine growth in agricultural value-added, industrial value-added, and aggregate investment respectively. ${ }^{31}$ These variables are taken from the World Development Indicators.

The results in Panel A show substantial, negative effects of temperature in poor countries on agricultural and industrial value-added. Column (1) shows that a $1^{\circ} \mathrm{C}$ higher temperature in poor countries is associated with 2.66 percentage points lower growth in agricultural output. For wealthier countries, the point estimate is substantially smaller and not statistically significant, showing 0.22 percentage points lower growth in agricultural output for each additional $1{ }^{\circ} \mathrm{C}$ of temperature. As might be expected, precipitation positively impacts agriculture - each additional $100 \mathrm{~mm}$ of annual rainfall is associated with 0.18 percentage points higher growth in agricultural output in poor countries and 0.16 percentage points higher growth in agricultural output in richer countries - though these effects are not statistically significant. ${ }^{32}$

Column (2) of Panel A shows negative temperature impacts on the growth of industrial value-added in poor countries. Specifically, a $1^{\circ} \mathrm{C}$ higher temperature in poor countries is associated with 2.04 percentage points lower growth in industrial output. In related work, Jones and Olken (2010) examine export growth in 2-digit trade data, and also find negative effects of temperature on both agricultural products and industrial products in poor countries. Many of the industrial sectors affected by temperature in the exports data, such as electronic equipment and light metal manufactures, are not downstream processors of agricultural products. Hsiang (2010)

\footnotetext{
${ }^{31}$ We find negative effects of similar magnitude on the residual category, services, which is typically computed as the difference between total value-added and the sum of agricultural and industrial value added (see online appendix).

${ }^{32}$ Note that we are estimating only the average impact of temperature and precipitation, without accounting for whether it was in the season that would most beneficial or harmful to agricultural production. This likely creates an errors-in-variables problem, which may suggest that we are understating the true effect of temperature and precipitation on agriculture (see, e.g. Shlenker and Roberts PNAS 2009).
} 
also documents similar impacts on industrial output in his study of temperature shocks in 28 Caribbean countries. The results on investment in column (3) also suggest negative impacts of temperature in poor countries, though the results are not statistically significant. ${ }^{33}$

Panel B examines the lag structure of these effects. For each dependent variable (growth in agriculture, growth in industry, and growth in investment), we present results with 1,5 , and 10 lags. For all three dependent variables, the impact effect - i.e., the coefficient on contemporaneous temperature - is negative and large, though the investment variable is not statistically significant. For agriculture, the point estimates of the cumulative effects, while imprecise, are somewhat smaller than the immediate effects, suggesting the presence of some combination of growth and level effects for these variables. For industrial value added, the point estimates of the cumulative effects are closer in magnitude to the immediate effect.

These findings on industrial value added reject a narrow view of climatic effects. While confirming agricultural effects, the results further show large shocks to industrial output growth in poor countries. There are several possible, non-mutually exclusive explanations for temperature's impact on industrial output. First, this effect could partly represent a demand-side spillover from the negative effect of temperature on agricultural output. Second, this effect may reflect labor productivity losses, consistent with a large literature documenting the impact of temperature on output in factory and other settings. For example, Graff Zivin and Niedell (2010) demonstrate substantial contractions in labor supply on hot days in those U.S. industries with high exposure to weather (e.g., those with work outdoors and those without access to air conditioning). ${ }^{34}$ Their estimated magnitudes are large: for high temperature exposure

\footnotetext{
${ }^{33}$ Note, however, that there is a weakly significant precipitation effect in rich countries. Using daily data on precipitation (NCC 2005), we find that having a larger number of days with very high precipitation has a significant negative effect on aggregate output in rich countries (see online appendix). One conjecture is that construction responds negatively to rain, providing the investment effect. Note also that aggregate investment in poor countries does show a statistically significant decline of 3.0 percentage points when using the full Penn World Tables sample, which is $50 \%$ larger.

${ }^{34}$ Building on classic ideas in economic development that link productivity to temperature (Montesquieu 1750, Marshall 1890), Huntington (1915) documented that high temperature reduces the productivity of piece-rate Connecticut factory workers and Florida cigar-makers. More recently, Link and Pepler (1970), Wyon (1976), Meese et al. (1982), and others have found substantial negative impacts of higher temperatures on the productivity of factory workers. More generally, the large literature on climate and productivity, which includes laboratory
} 
occupations, temperatures over 100 degrees Fahrenheit (37.7 degrees C) lead to 23\% lower labor supply than temperatures between 76-80 degrees Fahrenheit (24.4-26.6 degrees C). If poor countries' industrial sectors are more sensitive to temperature than those of rich countries (for example, because they are not air conditioned), then these types of labor supply or other labor productivity effects could explain the substantial impact of temperature on manufacturing that we observe.

\subsection{Political economy}

Temperature may also impact growth if increased temperature leads to political instability, which in turn may impede factor accumulation and productivity growth. Empirically, political instability is associated with lower economic growth (Alesina et al. 1996), and there is substantial empirical evidence that riots and protests are more likely in warmer weather (e.g., United States Riot Commission 1968; Carlsmith and Anderson 1979; Boyanowsky 1999), possibility suggesting a direct link between temperature and political instability. ${ }^{35}$ Alternatively, economic impacts of higher temperatures might provoke dissatisfied citizens to seek institutional change (Burke and Leigh 2010, Bruckner and Ciccone 2011).

We examine the impact of temperature on several measures of political instability. First, the Polity IV dataset (Marshall and Jaggers 2004) rates the political system in each country annually from -10 (fully autocratic) to +10 (fully democratic). This POLITY variable further designates "interregnum periods", which are years when the political system is in flux and no

experiments and experiments in actual work places (i.e. factories, call centers, and office buildings), robustly finds a decrement in work performance when temperatures exceed those associated with thermal neutrality. The review of Seppanen et al. (2003) finds a median $2 \%$ decrement in work performance per degree Celsius temperature rise above 25 degrees Celsius. Moreover, in a meta-analysis of more than 150 studies, Ramsey and Kwon (1992) distinguish between simple mental tasks (i.e. simple perpetual motor, reaction time) and more complex tasks (i.e. tracking, vigilance, dual tasks). While effects of heat stress appear limited or simple mental tasks, statistically significant effects appear at high temperatures for the second class of tasks. Simpler tasks may be less affected because when the body becomes impaired by or expends energy to counteract the negative impacts of heat stress (i.e. dehydration, increased sweating and loss of sodium, etc), the automatic processes in simple tasks are prioritized over complex cognitive tasks that are typically less essential for survival.

${ }^{35}$ Medical studies have documented that levels of platelet paroxitine - a chemical that blocks impulsivity and aggression - fall when temperatures increase and have linked low levels of platelet paroxitine to higher rates of aggression (Tihonen et al. 1997). Violent crime also increases with temperature (Jacob et al. 2007). 
clear political regime has emerged. We consider two dummy variables: one for any change in the POLITY variable, indicating a political change, and one for a POLITY interregnum period, indicating a period of political turmoil.

The second set of measures comes from the Archigos dataset on political leaders (Goemans et al. 2006). This dataset classifies the primary national political leader for each country and year and codes all leader transitions into two categories: "regular" transitions, which take place according to the prevailing institutional rules of the country, and "irregular" transitions (such as coups), which do not follow the prevailing institutional rules. We consider a dummy variable for years with leadership transitions, as well as separate dummy variables for regular and irregular transitions.

The results are presented in Table 6. Looking first at POLITY, an additional $1{ }^{\circ} \mathrm{C}$ in poor countries is associated with a 2.7 percentage point increase in the probability of any change in POLITY. ${ }^{36,37}$ The Archigos results show a similar pattern and are stronger statistically. A one degree rise of temperature raises the probability of leader transitions by 3.1 percentage points in poor countries (column 2). Moreover, this effect comes not from regular leadership transitions (column 3) but from irregular leader transitions - i.e. coups (column 4). This effect of 4.4 percentage points is large, as the baseline probability of an irregular leader transition is only 4.5 percent per year in poor countries. By contrast, we see no effects on leader transitions in rich countries.

Combined, the POLITY and Archigos data tell a similar story: higher temperatures are associated with political instability in poor countries. Whether temperature has direct effects on political instability, which in turn affects economic growth, or whether temperature has direct effects on economic growth, which in turn affects political instability - or both - is difficult to distinguish, since poor economic performance and political instability are likely mutually reinforcing. Nevertheless, the impact of temperature on political instability in poor countries is

\footnotetext{
${ }^{36}$ In the appendix, we decompose this change into contemporaneous increases in POLITY (towards democracy), decreases (towards autocracy), or shifts into interregnum periods (between regimes). We find about half of the changes induced by temperature are decreases in POLITY and about half are interregnum periods, though the decomposition is weak statistically. See Appendix Table A36.

${ }^{37}$ The results on precipitation appear smaller, but suggest that political change in poor countries is more likely in years with lower rainfall.
} 
suggestive of an institutional mechanism through which temperature might affect productivity growth, rather than just the level of income. ${ }^{38}$

The final columns of Table 6 consider the impact of temperature on conflict. We use the PRIO conflict data (PRIO 2006), which indicates for every country-year whether the country was involved in a high-intensity conflict (defined as $\geq 1,000$ conflict deaths / year) or a low-intensity conflict (defined as 25 to 1000 conflict deaths / year). Column (5) examines the start of conflicts (i.e., the probability a conflict begins given no conflict in the previous period), and column (6) examines the end of conflicts (i.e., the probability a conflict ends given conflict in the previous period). ${ }^{39}$ We find no significant effect of temperature on either the start or conclusion of conflicts. $^{40}$ The political impacts of temperature thus appear more concentrated in political instability rather than civil or interstate wars.

\section{Medium-run Estimates}

In this section, we re-examine the historical data to investigate temperature shifts over the medium run. The above, short-run panel estimates indicate substantial effects of temperature shocks in poor countries, with per-capita income growth falling approximately 1 percentage point for a $1{ }^{\circ} \mathrm{C}$ rise in temperature. In the medium run, the effect of sustained temperature increases might attenuate over time if economies adapt. On the other hand, sustained higher temperatures may reinforce growth-related problems by placing continued pressure on political systems or other relevant factors.

We therefore consider the longer-run analogue of our panel specification, examining the

\footnotetext{
${ }^{38}$ These results, emphasizing political instability, complement but differ from recent literature finding that weatherassociated output contractions predict democratization (Burke and Leigh 2010, Bruckner and Ciccone 2011). Here we look at a more general class of political changes and make no claim that the effects of temperature shocks are felt on political variables through an output channel.

${ }^{39}$ Given how rare conflicts are, we use year fixed effects rather than region-by-year fixed effects in these specifications.

${ }^{40}$ These results differ from Miguel et al. (2004), who find - also using the PRIO dataset - that greater precipitation is associated with a lower probability of conflict. We have successfully replicated the Miguel et al. results in our data, and find that the differences between the findings in Table 7 and those in Miguel et al. come from a different sample of countries (Miguel et al. examine only Sub-Saharan African countries from 1981-1999) and the fact that Miguel et al. use a somewhat different empirical specification from the one in Table 7. These replication results are presented in the online appendix.
} 
relationship between temperature changes and growth changes in the early and late periods in our dataset. There is substantial heterogeneity in temperature increases over this period, with countries such as Tunisia, Zambia, and Botswana warming by approximately $1{ }^{\circ} \mathrm{C}$ since the mid 1980s, while others such as Laos, Kenya, and Nigeria experienced almost no warming over the same period. We exploit this variation to ask whether countries with sustained warming saw sustained changes in growth.

Specifically, we estimate the following regression

$$
\bar{g}_{i 2}-\bar{g}_{i 1}=\alpha+\theta_{r}+\gamma\left(\bar{T}_{i 2}-\bar{T}_{i 1}\right)+\varepsilon_{i}
$$

where $\bar{g}_{i 1}$ is the mean growth rate in country $i$ in the early period (1970-1985 in our main specification), and $\bar{g}_{i 2}$ is the mean growth rate in the late period (1986-2000). ${ }^{41}$ Mean temperature and precipitation in these periods are $\bar{T}_{i 1}$ and $\bar{T}_{i 2}$, while $\theta_{r}$ captures region fixed effects and a dummy for being poor, and $\varepsilon_{i}$ is an independently distributed error term. This firstdifferenced regression is the longer-run version of the fixed effects panel model in equation (4). To see this, start with equation (4) with no lags, take averages of the left- and right-hand sides for a given period, and then first-difference. We have one observation per country, having differenced out any initial conditions or other fixed national characteristics that might influence growth. $^{42}$

A graphical version of the results is shown in Figure 2, and the regression results are shown in Table 7. Figure 2 plots the change in growth between the 1970-1985 and 1985-2000 against the change in average temperature during the same periods, separately for poor and rich countries, along with a simple regression line (and associated standard errors). The graphs show a statistically significant downward sloping relationship in poor countries, with no statistically significant relationship in rich countries. ${ }^{43}$

\footnotetext{
${ }^{41}$ We begin in the 1970s, rather than an earlier decade such as the 1960s, because we lose most of the poor countries in our sample when we extend the sample back to the 1960s. We present results for a variety of alternative time periods below.

${ }^{42}$ Note also that, in cross-section, average growth is substantially lower in warmer countries over this period. While interesting, this is less well identified than the first differenced results, which net out unobserved fixed country characteristics.

${ }^{43}$ The point estimates for rich countries suggest an upward slope, although it is not statistically significant, and flattens further when using median regression (see Table 7).
} 
Turning to Table 7, the baseline specification compares the 1970-1985 period to the 1986-2000 period and shows substantial, statistically significant negative effects of warming on poor countries. In column (1), a temperature rise of $1^{\circ} \mathrm{C}$ reduces annual growth in poor countries by 1.9 percentage points. The inclusion of region fixed effects does not substantially change this effect, as shown in column (2), though the result is no longer statistically significant. When we use median regressions to reduce the impact of outliers (columns 3 and 4), the estimated impact for poor countries becomes slightly larger and substantially more statistically significant. Columns 5 through 7 use alternative comparison years. In all cases the temperature effect on poor countries is - as in the sample in Column 2 which uses the same set of fixed effects negative but not statistically significant. When we split the sample into Sub-Saharan African countries (column 9) and all other countries (column 10), we find similar effects in both samples, though the estimates are not statistically significant. ${ }^{44}$ Using PWT data instead of WDI data finds that $1^{\circ} \mathrm{C}$ reduces annual growth in poor countries by 2.3 percentage points (column 11). Overall, this analysis provides some suggestive evidence that the effects seen in the annual data persist over the medium run. Put another way, we find little evidence that poor countries eliminate all negative consequences of warming over the time horizons considered here.

\section{Discussion}

\subsection{Temperature and economic development}

The negative cross-sectional association between temperature and per-capita income (see Figure 1) has long been known (e.g., Huntington 1915). Yet there has been a vigorous debate over whether this correlation is due to a direct impact of temperature on economic activity (e.g., Sachs 2003), or whether some third variable (e.g., a country's institutions) drives prosperity in contemporary times, leaving little or no room for geography (e.g., Acemoglu, Johnson and Robinson 2002; Rodrik, Subramanian and Trebbi 2004). This debate has primarily proceeded by treating temperature variables as fixed for a given country, which makes testing these alternative hypotheses challenging.

By using temperature variation within countries, we can better identify its effects. Our results show that temperature per se has an important impact on national economic performance.

\footnotetext{
${ }^{44}$ As in Table 4 above, because nearly all countries in Sub-Saharan Africa are poor, we do not separately distinguish between rich and poor countries when focusing on this region.
} 
While not ruling out many other forces that may play important roles in economic development, the evidence here rejects the hypothesis that temperature does not influence national production. Moreover, the estimated impacts are large in magnitude - in fact, more than large enough to explain the cross-sectional temperature-income relationship between rich and poor countries. To see this, recall from that the cross-sectional relationship shows a decline in per-capita income of $8.5 \log$ points, or about 8 percent, for a $1^{\circ} \mathrm{C}$ increase in temperature (see Figure 1). Our panel estimates show that a $1^{\circ} \mathrm{C}$ temperature increase reduces poor country growth rates by 1.3 percentage points. In a world with no adaptation, our panel estimates imply that cross-country temperature differences would need to be sustained for only 7 years to generate the crosssectional correlation between temperature and per-capita income seen in Figure $1 .{ }^{45}$ In practice, adaptation may mitigate these effects substantially in the long run.

\subsection{Building estimates for the impact of future climate change}

Estimating the future implications of climatic change is a difficult exercise given numerous uncertainties, both about the extent and nature of climatic change and in the economic effects that may ensue. Our estimates use recent historical evidence to inform the short- and medium-run consequences of temperature increases, but bridging to long-run implications is more challenging. First, countries may adapt to permanent changes in climate more successfully than they adapt to the annual or decade-long temperature shocks that we examine empirically. Adaptation can take place at a local level but also at a global level, where new adaptive technologies may be developed that find wide-scale use. ${ }^{46}$ Second, several potential effects of future climatic change, including potential effects on sea levels, biodiversity, and storm frequency, are not captured within our historical analysis. Third, global-scale general equilibrium effects, including adjustments in trade patterns and convergence forces, may offset asymmetric national effects on poor countries. ${ }^{47}$

\footnotetext{
${ }^{45}$ Dell, Jones, and Olken (2009) considers how explicit assumptions about adaptation, convergence, and other forces over the long-run can reconcile short and long-run empirical relationships between temperature and income.

${ }^{46}$ To investigate the possibility of global adaptation, we have looked at whether the estimated impacts of temperature become less pronounced over time. While the point estimates suggest smaller temperature impacts in more recent decades, the difference is not statistically significant. See Appendix Tables A31 and A32.

${ }^{47}$ A key advantage of the panel analysis in this paper is to enhance identification by sweeping out fixed effects for country and time. However, this approach by necessity eliminates the capacity to estimate global-scale effects.
} 
While tackling these challenges is beyond the scope of this paper, its findings do suggest important ways in which future implementations of climate-economy models could be modified to better match the historical climate-economy relationship. First, current climate-economy models are built around a relatively narrow set of channels - primarily agriculture - through which climate could impact economic activity. Our analysis finds large effects - in industrial value-added and political stability - that are not considered by most current IAM climateeconomy analyses. Second, IAM approaches often build underlying sector-specific models from evidence of behavior in rich countries. Our results, whether looking at aggregate output or underlying channels, repeatedly demonstrate that poor countries experience extremely different (and negative) effects compared to rich countries, so extrapolating analyses of rich-countries is likely to understate effects in poorer regions. Finally, most existing literature assumes that temperature will affect the level of output, as opposed to the growth rate of output. In our method, we consider the possibility of both level and growth effects. Because growth effects compound over time, even modest growth effects can accumulate into large income effects.

\section{Conclusion}

This paper examines the historical relationship between temperature fluctuations and economic growth. We find substantial effects of temperature shocks, but only in poor countries. In poor countries, a $1^{\circ} \mathrm{C}$ rise in temperature in a given year reduces economic growth by 1.3 percentage points on average. The estimates suggest that climate change may affect the rate of economic growth, rather than just the level of output. Moreover, estimates using medium-run shifts from 1970 to 2000 rather than annual variation produce similar though noisier estimates, suggesting that adaptation may not undo these effects in the medium term.

By focusing on fluctuations in temperature, we seek to inform old debates over temperature's role in economic development and new debates over future impacts of climate change. Our findings of large effects of temperature shocks on poor countries provide counterevidence to claims that temperature does not influence national production. While higher temperatures reduce agricultural output in poor countries, we also find that they lead to reductions in industrial output and political stability. These results underscore the breadth of mechanisms underlying the climate-economy relationship and emphasize channels not usually considered in the aggregate climate literature. Further work is needed to identify precise causal mechanisms surrounding each of these channels. While teasing out the mechanisms is 
challenging, this paper suggests such analysis is of first-order importance, as the economic effects in poor countries appear large.

Given uncertainty over adaptation, international spillovers, technical change, and other issues, the estimates here - driven primarily from short-run fluctuations in temperature - cannot alone provide precise predictions about the estimated impacts of future climate change. The results do, however, provide clear guidance on critical economic dimensions that integrated assessment models and other attempts to think about global climate change should incorporate. A credible model should be able to match the historical moments in the data uncovered here: the stark differences between rich and poor countries; the possibility of growth effects rather than just level effects; and the possibility that climate change will affect the economy outside of agriculture. Incorporating these effects into current models of climate change will yield predictions that more closely match historical evidence about the relationship between temperature and economic performance.

\section{References}

Acemoglu, Daron, Simon Johnson, and James Robinson. "The Colonial Origins of Comparative Development: An Empirical Investigation,” American Economic Review, 1369-1401, 2001. Acemoglu, Daron, Simon Johnson, and James Robinson. "Reversal of Fortune: Geography and Institutions in the Making of the Modern World Income Distribution," Quarterly Journal of Economics 117, 1231-1294.

Adams, Richard et al. "Global Climate Change and US Agriculture," Nature 345, 219-224, 1990. Alesina, Alberto, Sule Ozler, Nouriel Roubini, and Philip Swagel. "Political Instability and Economic Growth," Journal of Economic Growth 1(2), 1996.

Balk, Deborah et al. Center for International Earth Science Information Network (CIESIN), Columbia University; International Food Policy Research Institute (IFPRI), the World Bank; and Centro Internacional de Agricultura Tropical (CIAT), 2004. Global Rural-Urban Mapping Project (GRUMP), Palisades, NY: CIESIN, Columbia University. Available at http://sedac.ciesin.columbia.edu/gpw, 2004. 
Barrios, Salvador, Luisito Bertinelli, and Eric Strobl, "Trends in Rainfall and Economic Growth in Africa: A Neglected Cause of the Growth Tragedy," Review of Economics and Statistics, 2010.

Bond, Stephen R., Asli Leblebicioglu, and Fabio Schiantarelli, "Capital Accumulation and Growth: A New Look at the Empirical Evidence," Journal of Applied Econometrics 25(7), 2010.

Boyanowsky, Ehor. "Violence and Aggression in the Heat of Passion and in Cold Blood: The Ecs-TC Syndrome,” International Journal of Law and Psychiatry 22(3): 257-271, 1999.

Brohan, Phillip, John Kennedy, I. Haris, Simon Tett and Pete Jones. "Uncertainty estimates in regional and global observed temperature changes: A new data set from 1850," Journal of Geophysical Research 111, 2006.

Brückner, Markus and Antonio Ciccone, "Rain and the Democratic Window of Opportunity," Econometrica 79, 2011.

Burke, Paul and Andrew Leigh, "Do Output Contractions Trigger Democratic Change?" American Economic Journal: Macroeconomics 2(4), 2010.

Cameron, Colin, Jonah Gelbach and Douglas Miller, "Robust Inference with Multi-way Clustering,” Journal of Business and Economic Statistics 29(2), 238-249, 2011.

Carlsmith, J. Merrill and Craig A. Anderson, "Ambient Temperature and the Occurrence of Collective Violence: A New Analysis,” Journal of Personality and Social Psychology 37 (3), 337-344, 1979.

Curriero, Frank C., Karlyn Heiner, Jonathan Samet, Scott Zeger, Lisa Strug, Jonathan A.Patz. “Temperature and Mortality in 11 Cities of the Eastern United States," American Journal of Epidemiology 155(1):80-87, 2002.

Dell, Melissa, Benjamin F. Jones and Benjamin A. Olken. "Temperature and Income:

Reconciling New Cross-Sectional and Panel Estimates," American Economic Review Papers and Proceedings 99, 198-204, 2009.

Deschenes, Olivier and Michael Greenstone, “The Economic Impacts of Climate Change: Evidence from Agricultural Output and Random Fluctuations in Weather," American Economic Review 97, 354-385, 2007. 
Deschenes, Olivier and Enrico Moretti, "Extreme Weather Events, Mortality, and Migration", Review of Economics and Statistics 91(4), 659-681, 2010.

Field, Simon. "The Effect of Temperature on Crime," The British Journal of Criminology 32, 340-351, 1992.

Gallup, John L. and Jeffrey D. Sachs. "The economic burden of malaria," The American Journal of Tropical Medicine and Hygiene, 64, 85-96, 2001.

Gallup, John L., Andrew Mellinger, and Jeffrey D. Sachs, "Geography and Economic Development," International Regional Science Review, Vol. 22, No. 2, pp. 179-232, August 1999.

Gates, Warren. "The Spread of Ibn Khaldun's ideas on Climate and Culture," Journal of History and Ideas 28, 415-422, 1967.

Graff Zivin, Joshua and Matthew J. Neidell. "Temperature and the Allocation of Time: Implications for Climate Change,” NBER Working Paper No. 15717, 2010.

Goemans, Hein, Kristian Gleditsch and Giacomo Chiozza. "Archigos: A Database of Leaders 1875-2004", http://mail.rochester.edu/ hgoemans/data, 2006.

Guiteras, Raymond. "The Impact of Climate Change on Indian Agriculture," mimeo, MIT Department of Economics, 2007.

Hancock, Peter and I. Vasmatzidis. "Effects of heat stress on cognitive performance: the current state of knowledge," International Journal of Hyperthermia 19 (3), 355-372, 2003.

Heston, Alan, Robert Summers and Bettina Aten, Penn World Table Version 6.2, Center for International Comparisons of Production, Income and Prices at the University of Pennsylvania, September 2006.

Hornbeck, Richard, "The Enduring Impact of the American Dust Bowl: Short and Long-run Adjustments to Environmental Catastrophe," American Economic Review, forthcoming. Huntington, Ellsworth. Civilization and Climate, New Haven, CT: Yale University Press, 1915. Hsiang, Solomon M. "Temperatures and Cyclones Strongly Associated with Economic Production in the Caribbean and Central America," Proceedings of the National Academy of Sciences, 2010. 
Intergovernmental Panel on Climate Change. IPCC Fourth Assessment Report, Working Groups I, II, and III (http://www.ipcc.ch/), 2007.

Jacob, Brian, Lars Lefgren and Enrico Moretti. "The Dynamics of Criminal Behavior: Evidence from Weather Shocks" Journal of Human Resources, 2007.

Johnson, Simon, William Larson, Chris Papageorgiou, and Arvind Subramanian. "Is Newer Better? Penn World Table Revisions and Their Impact on Growth Estimates," NBER Working Paper \#15455, 2009.

Jones, Benjamin F. and Benjamin A. Olken, "Climate Shocks and Exports,' American Economic Review Papers and Proceedings, forthcoming 2010.

Lavely, William and R. Bin Wong. "Revising the Malthusian Narrative: The Comparative Study of Population Dynamics in Late Imperial China," The Journal of Asian Studies 57(3), 716$718,1998$.

Link James and Robert Pepler. 1970. "Associated fluctuations in daily temperature, productivity and absenteeism,” No 2167 RP-57, ASHRAE Transactions, vol 76, Part II, 326-337, 1970.

Maccini, Sharon and Dean Yang, "Under the Weather: Health, Schooling, and Economic Consequences of Early-Life Rainfall,” American Economic Review 99 (3), 1006-1026, June 2009.

Marshall, Alfred. Principles of Economics. London: Macmillan and Co. 1920 [1890].

Marshall, Monty G., and Keith Jaggers. Polity IV Project, Integrated Network for Societal Conflict Research Program and Center for International Development and Conflict Management, University of Maryland, 2004.

Matsuura, Kenji and Cort Willmott. Terrestrial Air Temperature and Precipitation: 1900-2006 Gridded Monthly Time Series, Version 1.01, University of Delaware, http://climate.geog.udel.edu/ climate/, 2007.

Meehl, Gerald, Claudia Tebaldi, and Doug Nychka. "Changes in frost days in simulations of 21st century climate." Climate Dynamics, Vol. 23, No. 5, 495-511, 2004.

Meese, G., R. Kok, M. Lewis, and D. Wyon. "Effects of Moderate Cold and Heat Stress on Factory Workers in Southern Africa” South Africa Journal of Science 78: 189-197, 1982. 
Mendelsohn, Robert, Wendy Morrison, Michael Schlesinger and Natalia Andronova. "Countryspecific market impacts of climate change," Climatic Change 45(3-4): 553-569, 2000.

Mendelsohn, Robert, Ariel Dinar, and Apurva Sanghi. "The Effect of Development on the Climate Sensitivity of Agriculture," Environmental and Development Economics 6, 85-101, 2001.

Miguel, Edward, Shanker Satyanath and Ernest Sergenti. "Economic Shocks and Civil Conflict: An Instrumental Variables Approach,” Journal of Political Economy 112(4), 725-753, 2004. Montesquieu, Charles de. The Spirit of Laws, 1750.

Neng, Shi, Chen Luwen, and Xia Dongdong. "A Preliminary Study on the Global Land Annual Precipitation Associated with ENSO during 1948-2000," Advances in Atmospheric Sciences 19: 993-1003, 2002.

New, Mark, Martin Todd, Mike Hulme, and Phil Jones. "Precipitation measurements and trends in the twentieth century." International Journal of Climatology 21, 1899-1922, 2001.

Nicholls, Robert and Stephen Leatherman (eds.) "Potential Impacts of Accelerated Sea-Level Rise on Developing Countries," Journal of Coastal Research, Special Issue No. 14, 1995.

Nordhaus, William. "Geography and Macroeconomics: New Data and Findings," Proceedings of the National Academy of Science 103, 3510-3517, 2006.

Nordhaus, William and Joseph Boyer, Warming the World: The Economics of the Greenhouse Effect, Cambridge, MA: MIT Press, 2000.

PRIO, Armed Conflict Data Version 4. Available at http://new.prio.no/CSCW-Datasets/Data-onArmed-Conflict/UppsalaPRIO-Armed-Conflicts-Dataset/, 2006.

Ramsey, Jerry and Y. Kwon. "Recommended alert limits for perceptual motor loss in hot environments," International Journal of Industrial Ergonomics 9 (3), 245 - 257, 1992.

Rodrik, Dani, Arvind Subramanian, and Francesco Trebbi, "Institutions Rule: The Primacy of Institutions Over Geography and Integration in Economic Development," Journal of Economic Growth 9, 131-165, 2004.

Sachs, Jeffrey D. “Institutions Don't Rule: Direct Effects of Geography on Per-Capita Income," National Bureau of Economic Research working paper No. 9490, 2003.

Sachs, Jeffrey and Pia Malaney. "The economic and social burden of malaria," Nature, 415, 
680-685, 2002.

Sachs, Jeffrey D. and Andrew Warner. "Sources of Slow Growth in African Economies," Journal of African Economies, 6, 335-76, 1997.

Seppanen, Olli, William Fisk, and D. Faulkner. "Cost benefit analysis of the night-time ventilative cooling in office building," Healthy Buildings 2003 Conference, Singapore (SG), 12/07/2003 - 12/11/2003, 2003.

Schlenker, Wolfram, W. Michael Hanemann, and Anthony C. Fisher, "The Impact of Global Warming on U.S. Agriculture: An Econometric Analysis of Optimal Growing Conditions," Review of Economics and Statistics 88 (1), 113-125, February 2006.

Schlenker, Wolfram and Michael J. Roberts, "Nonlinear Effects of Weather on Corn Yields." Review of Agricultural Economics 28 (3), 391-398, June 2006.

Schlenker, Wolfram and Michael J. Roberts, "Nonlinear Temperature Effects indicate Severe Damages to U.S. Crop Yields under Climate Change," Proceedings of the National Academy of Sciences 106 (37), 15594-15598, September 152009.

Stern, Nicholas, The Economics of Climate Change: The Stern Review, Cambridge, England: Cambridge University Press, 2007.

Tol, Richard. "Estimates of the damage costs of climate change - part II: dynamic estimates," Environmental and Resource Economics 21, 135-160, 2002.

U.S. Riot Commission. Report of the National Advisory Commission on Civil Disorders. New York: Bantam Books, 1968.

University Corporation for Atmospheric Research (UCAR). GIS Climate Change Scenarios, http://www.gisclimatechnage.org, September 2007.

World Bank, 2007 World Development Indicators Online Edition, 2007.

Wrigley, Edward Anthony and Robert Schofield. The Population History of Britain 1541-1871: A Reconstruction. London, England: Edward Arnold, 1981.

Wyon, David. "Assessing the effects of moderate heat and cold stress on human efficiency," Paper no. 6 of Proceedings of the Symposium, Factories for Profit - Environmental Design, National Building Research Institute, Pretoria, September 14-16 1976.

Young, Alwyn. "The African Growth Miracle," London School of Economics mimeo, 2009. 
Table 1: Observed temperature and precipitation variation, 1950-2003

Raw data

After removing worldwide year fixed effects

After removing region $\times$ year and poor $\times$ year fixed effects

Raw data

After removing worldwide year fixed effects

After removing region $\times$ year and poor $\times$ year fixed effects

Proportion of country-years with temperature [
0.25
0.570

0.570

0.50

0.294

0.75

0.144

0.085

1.00

0.065

0.034

0.054

0.020

Proportion of country-years with precipitation [... $100 \mathrm{~mm}$ units above/below country mean:

$\begin{array}{cccccc}1 & 2 & 3 & 4 & 5 & 6 \\ 0.480 & 0.229 & 0.123 & 0.072 & 0.044 & 0.029 \\ 0.495 & 0.222 & 0.113 & 0.063 & 0.039 & 0.025 \\ & & & & & 0.022\end{array}$


Table 2: Main panel results

\begin{tabular}{|c|c|c|c|c|c|}
\hline \multicolumn{6}{|c|}{ Dependent variable is the annual growth rate } \\
\hline & $(1)$ & (2) & (3) & (4) & $(5)$ \\
\hline Temperature & $\begin{array}{l}-0.325 \\
(0.285)\end{array}$ & $\begin{array}{c}0.261 \\
(0.312)\end{array}$ & $\begin{array}{c}0.262 \\
(0.311)\end{array}$ & $\begin{array}{c}0.172 \\
(0.294)\end{array}$ & $\begin{array}{l}0.561 * \\
(0.319)\end{array}$ \\
\hline \multicolumn{6}{|l|}{ Temperature interacted with... } \\
\hline Poor country dummy & & $\begin{array}{c}-1.655^{* * * *} \\
(0.485)\end{array}$ & $\begin{array}{c}-1.610 * * * \\
(0.485)\end{array}$ & $\begin{array}{c}-1.645^{* * *} \\
(0.483)\end{array}$ & $\begin{array}{c}-1.806 * * * \\
(0.456)\end{array}$ \\
\hline Hot country dummy & & & & $\begin{array}{c}0.237 \\
(0.568)\end{array}$ & \\
\hline Agricultural country dummy & & & & & $\begin{array}{c}-0.371 \\
(0.409)\end{array}$ \\
\hline Precipitation & & & $\begin{array}{c}-0.083 * \\
(0.050)\end{array}$ & $\begin{array}{c}-0.228 * * * \\
(0.074)\end{array}$ & $\begin{array}{c}-0.105 * * \\
(0.053)\end{array}$ \\
\hline \multicolumn{6}{|l|}{ Precipitation interacted with... } \\
\hline Poor country dummy & & & $\begin{array}{c}0.153 * \\
(0.078)\end{array}$ & $\begin{array}{c}0.160 * * \\
(0.075)\end{array}$ & $\begin{array}{l}0.145^{*} \\
(0.087)\end{array}$ \\
\hline Hot country dummy & & & & $\begin{array}{c}0.185 * * \\
(0.078)\end{array}$ & \\
\hline Agricultural country dummy & & & & & $\begin{array}{c}0.010 \\
(0.085)\end{array}$ \\
\hline Observations & 4924 & 4924 & 4924 & 4924 & 4577 \\
\hline Within R-squared & 0.00 & 0.00 & 0.00 & 0.01 & 0.01 \\
\hline R-squared & 0.22 & 0.22 & 0.22 & 0.22 & 0.24 \\
\hline Temperature effect in poor countries & & $\begin{array}{r}-1.394 * * * \\
(0.369)\end{array}$ & $\begin{array}{c}-1.347 * * * \\
(0.361)\end{array}$ & $\begin{array}{c}-1.473 * * * \\
(0.396)\end{array}$ & $\begin{array}{c}-1.245 * * * \\
(0.404)\end{array}$ \\
\hline Precipitation effect in poor countries & & & $\begin{array}{r}0.069 \\
(0.052)\end{array}$ & $\begin{array}{r}-0.0677 \\
(0.071)\end{array}$ & $\begin{array}{c}0.0401 \\
(0.083)\end{array}$ \\
\hline
\end{tabular}

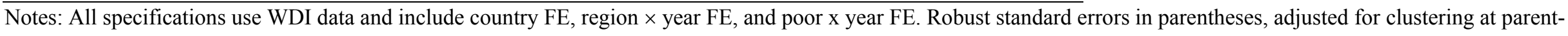

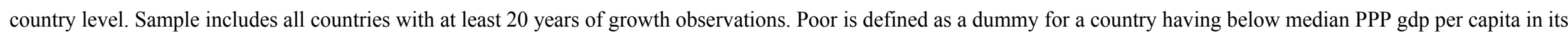

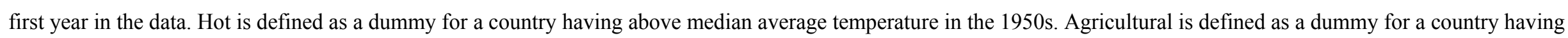
above median share of GDP in agriculture in 1995. Temperature is in degrees Celsius and precipitation is in units of 100mm per year.

* significant at $10 \% ; * *$ significant at $5 \%$;** significant at $1 \%$ 
Table 3: Models with lags

\begin{tabular}{|c|c|c|c|c|c|c|c|c|c|c|}
\hline & $\begin{array}{c}(1) \\
\text { No lags }\end{array}$ & $\begin{array}{c}(2) \\
1 \mathrm{lag} \\
\end{array}$ & $\begin{array}{c}(3) \\
3 \text { lags } \\
\end{array}$ & $\begin{array}{c}(4) \\
5 \text { lags } \\
\end{array}$ & $\begin{array}{c}(5) \\
10 \text { lags } \\
\end{array}$ & $\begin{array}{c}(6) \\
\text { No lags } \\
\end{array}$ & $\begin{array}{c}(7) \\
1 \mathrm{lag} \\
\end{array}$ & $\begin{array}{c}(8) \\
3 \text { lags } \\
\end{array}$ & $\begin{array}{c}(9) \\
5 \text { lags } \\
\end{array}$ & $\begin{array}{c}(10) \\
10 \text { lags } \\
\end{array}$ \\
\hline Temperature $\times$ Poor & $\begin{array}{c}-1.394 * * * \\
(0.408)\end{array}$ & $\begin{array}{c}-1.610^{* * *} \\
(0.525)\end{array}$ & $\begin{array}{c}-1.538 * * * \\
(0.559)\end{array}$ & $\begin{array}{c}-1.555^{* * *} \\
(0.572)\end{array}$ & $\begin{array}{c}-1.597 * * * \\
(0.565)\end{array}$ & $\begin{array}{c}-1.347 * * * \\
(0.408)\end{array}$ & $\begin{array}{c}-1.559 * * * \\
(0.522)\end{array}$ & $\begin{array}{c}-1.495^{* * *} \\
(0.557)\end{array}$ & $\begin{array}{c}-1.514 * * * \\
(0.577)\end{array}$ & $\begin{array}{c}-1.580 * * * \\
(0.579)\end{array}$ \\
\hline L2: Temperature $\times$ Poor & & & $\begin{array}{c}-0.331 \\
(0.554)\end{array}$ & $\begin{array}{c}-0.334 \\
(0.566)\end{array}$ & $\begin{array}{c}-0.368 \\
(0.580)\end{array}$ & & & $\begin{array}{c}-0.324 \\
(0.565)\end{array}$ & $\begin{array}{c}-0.338 \\
(0.570)\end{array}$ & $\begin{array}{c}-0.354 \\
(0.586)\end{array}$ \\
\hline L3: Temperature $\times$ Poor & & & $\begin{array}{c}-0.056 \\
(0.457)\end{array}$ & $\begin{array}{c}-0.105 \\
(0.480)\end{array}$ & $\begin{array}{c}-0.175 \\
(0.489)\end{array}$ & & & $\begin{array}{c}-0.008 \\
(0.460)\end{array}$ & $\begin{array}{c}-0.064 \\
(0.489)\end{array}$ & $\begin{array}{c}-0.152 \\
(0.506)\end{array}$ \\
\hline Temperature $\times$ Rich & $\begin{array}{c}0.261 \\
(0.312)\end{array}$ & $\begin{array}{c}0.206 \\
(0.323)\end{array}$ & $\begin{array}{c}0.203 \\
(0.320)\end{array}$ & $\begin{array}{c}0.227 \\
(0.330)\end{array}$ & $\begin{array}{c}0.219 \\
(0.348)\end{array}$ & $\begin{array}{c}0.262 \\
(0.311)\end{array}$ & $\begin{array}{c}0.215 \\
(0.322)\end{array}$ & $\begin{array}{c}0.212 \\
(0.322)\end{array}$ & $\begin{array}{c}0.235 \\
(0.338)\end{array}$ & $\begin{array}{c}0.234 \\
(0.356)\end{array}$ \\
\hline L1: Temperature $\times$ Rich & & $\begin{array}{c}0.135 \\
(0.300)\end{array}$ & $\begin{array}{c}0.148 \\
(0.298)\end{array}$ & $\begin{array}{c}0.143 \\
(0.297)\end{array}$ & $\begin{array}{c}0.166 \\
(0.317)\end{array}$ & & $\begin{array}{c}0.137 \\
(0.298)\end{array}$ & $\begin{array}{c}0.149 \\
(0.299)\end{array}$ & $\begin{array}{c}0.143 \\
(0.299)\end{array}$ & $\begin{array}{c}0.168 \\
(0.323)\end{array}$ \\
\hline L2: Temperature $\times$ Rich & & & $\begin{array}{c}0.131 \\
(0.249)\end{array}$ & $\begin{array}{c}0.165 \\
(0.257)\end{array}$ & $\begin{array}{c}0.158 \\
(0.263)\end{array}$ & & & $\begin{array}{c}0.143 \\
(0.251)\end{array}$ & $\begin{array}{c}0.181 \\
(0.262)\end{array}$ & $\begin{array}{c}0.172 \\
(0.273)\end{array}$ \\
\hline L3: Temperature $\times$ Rich & & & $\begin{array}{c}-0.234 \\
(0.267)\end{array}$ & $\begin{array}{c}-0.100 \\
(0.271)\end{array}$ & $\begin{array}{l}-0.129 \\
(0.277)\end{array}$ & & & $\begin{array}{c}-0.258 \\
(0.269)\end{array}$ & $\begin{array}{c}-0.110 \\
(0.277)\end{array}$ & $\begin{array}{l}-0.137 \\
(0.286)\end{array}$ \\
\hline Includes precipitation vars. & NO & NO & NO & $\mathrm{NO}$ & NO & YES & YES & YES & YES & YES \\
\hline Observations & 4924 & 4924 & 4920 & 4916 & 4906 & 4924 & 4924 & 4920 & 4916 & 4906 \\
\hline R-squared & 0.22 & 0.22 & 0.22 & 0.22 & 0.23 & 0.22 & 0.22 & 0.23 & 0.23 & 0.23 \\
\hline Within R-squared & 0.01 & 0.00 & 0.00 & 0.00 & 0.01 & 0.00 & 0.01 & 0.01 & 0.01 & 0.01 \\
\hline $\begin{array}{l}\text { Sum of all temp. coeff. } \\
\text { in poor countries } \\
\text { Sum of all temp. coeff. } \\
\text { in rich countries }\end{array}$ & $\begin{array}{c}-1.394 * * * \\
(0.408) \\
0.261 \\
(0.312)\end{array}$ & $\begin{array}{c}-1.096 * * * \\
(0.418) \\
0.341 \\
(0.400)\end{array}$ & $\begin{array}{c}-1.284 * * * \\
(0.494) \\
0.248 \\
(0.528)\end{array}$ & $\begin{array}{c}-1.235 * * \\
(0.527) \\
-0.18 \\
(0.566)\end{array}$ & $\begin{array}{c}-1.171 * \\
(0.611) \\
0.152 \\
(0.786)\end{array}$ & $\begin{array}{c}-1.347 * * * \\
(0.408) \\
0.262 \\
(0.311)\end{array}$ & $\begin{array}{c}-0.983 * * \\
(0.416) \\
0.352 \\
(0.396)\end{array}$ & $\begin{array}{c}-1.131 * * \\
(0.489) \\
0.247 \\
(0.521)\end{array}$ & $\begin{array}{c}-1.041 * * \\
(0.530) \\
-0.191 \\
(0.546)\end{array}$ & $\begin{array}{l}-0.858 \\
(0.647) \\
-0.189 \\
(0.758)\end{array}$ \\
\hline
\end{tabular}

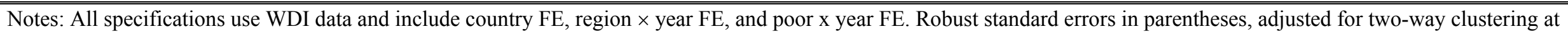

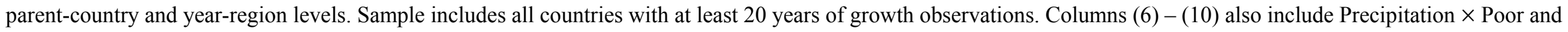

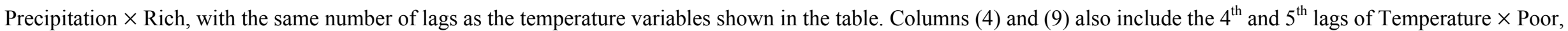

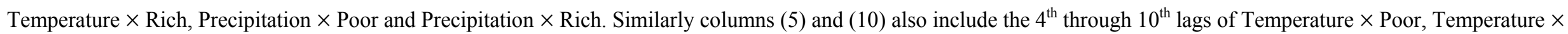

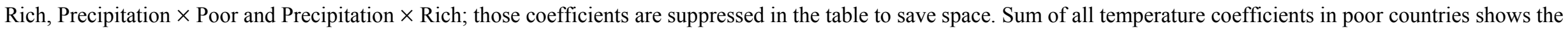

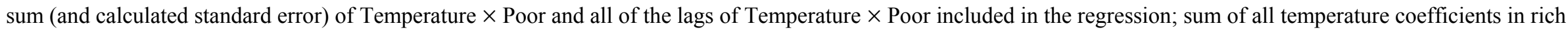
countries is calculated analogously. $*$ significant at $10 \% ; * *$ significant at $5 \% ; * * *$ significant at $1 \%$ 
Table 4: Alternative specifications of panel results

\begin{tabular}{|c|c|c|c|c|c|c|c|c|c|c|}
\hline & (1) & (2) & (3) & (4) & (5) & (6) & (7) & (8) & (9) & $(10)$ \\
\hline & Baseline & $\begin{array}{l}\text { All FE and } \\
\text { country } \\
\text { specific } \\
\text { trends }\end{array}$ & $\begin{array}{l}\text { Country FE } \\
\text { and } \\
\text { Region } \times \text { Yr } \\
\text { FE only }\end{array}$ & $\begin{array}{c}\text { Country FE } \\
\text { and Year } \\
\text { FE only }\end{array}$ & $\begin{array}{c}\text { Balanced } \\
\text { sample: } \\
1971 \text { - } 2003\end{array}$ & $\begin{array}{c}\text { Add } \\
\text { countries } \\
\text { with }<20 \\
\text { years of } \\
\text { data }\end{array}$ & $\begin{array}{l}\text { GDP data } \\
\text { from PWT }\end{array}$ & $\begin{array}{c}\text { Area- } \\
\text { weighted } \\
\text { climate data }\end{array}$ & $\begin{array}{l}\text { Sub- } \\
\text { Saharan } \\
\text { Africa } \\
\text { Only }\end{array}$ & $\begin{array}{l}\text { Sub- } \\
\text { Saharan } \\
\text { Africa } \\
\text { Excluded }\end{array}$ \\
\hline \multicolumn{11}{|l|}{ Panel A: Models with no lags } \\
\hline Temp. immediate effect - Poor & $\begin{array}{c}-1.347 * * * \\
(0.408)\end{array}$ & $\begin{array}{c}-1.723 * * * \\
(0.603)\end{array}$ & $\begin{array}{c}-0.798 * * \\
(0.392)\end{array}$ & $\begin{array}{c}-0.869 * * * \\
(0.320)\end{array}$ & $\begin{array}{c}-1.377 * * * \\
(0.484)\end{array}$ & $\begin{array}{c}-1.158 * * * \\
(0.424)\end{array}$ & $\begin{array}{c}-0.860 * * * \\
(0.299)\end{array}$ & $\begin{array}{c}-0.891 * * \\
(0.347)\end{array}$ & $\begin{array}{c}-1.881 * * * \\
(0.631)\end{array}$ & $\begin{array}{l}-0.904 * \\
(0.531)\end{array}$ \\
\hline Temp. immediate effect - Rich & $\begin{array}{c}0.262 \\
(0.311)\end{array}$ & $\begin{array}{c}0.417 \\
(0.473)\end{array}$ & $\begin{array}{l}-0.001 \\
(0.318)\end{array}$ & $\begin{array}{c}0.022 \\
(0.296)\end{array}$ & $\begin{array}{c}0.387 \\
(0.323)\end{array}$ & $\begin{array}{c}0.595 \\
(0.381)\end{array}$ & $\begin{array}{c}0.343 \\
(0.228)\end{array}$ & $\begin{array}{c}0.480 * * \\
(0.220)\end{array}$ & & $\begin{array}{c}0.295 \\
(0.323)\end{array}$ \\
\hline Precip. immediate effect - Poor & $\begin{array}{c}0.070 \\
(0.058)\end{array}$ & $\begin{array}{c}0.026 \\
(0.137)\end{array}$ & $\begin{array}{c}0.057 \\
(0.051)\end{array}$ & $\begin{array}{c}0.049 \\
(0.047)\end{array}$ & $\begin{array}{c}0.040 \\
(0.084)\end{array}$ & $\begin{array}{c}0.029 \\
(0.051)\end{array}$ & $\begin{array}{c}0.050 \\
(0.069)\end{array}$ & $\begin{array}{c}0.074 \\
(0.063)\end{array}$ & $\begin{array}{c}0.131 \\
(0.111)\end{array}$ & $\begin{array}{c}0.032 \\
(0.071)\end{array}$ \\
\hline Precip. immediate effect - Rich & $\begin{array}{c}-0.083 * \\
(0.050)\end{array}$ & $\begin{array}{l}-0.066 \\
(0.089)\end{array}$ & $\begin{array}{l}-0.063 \\
(0.050)\end{array}$ & $\begin{array}{l}-0.042 \\
(0.046)\end{array}$ & $\begin{array}{l}-0.101 * \\
(0.058)\end{array}$ & $\begin{array}{l}-0.022 \\
(0.061)\end{array}$ & $\begin{array}{l}-0.074 \\
(0.060)\end{array}$ & $\begin{array}{l}-0.087 \\
(0.056)\end{array}$ & & $\begin{array}{c}-0.087^{*} \\
(0.053)\end{array}$ \\
\hline Observations & 4924 & 4924 & 4924 & 4924 & 2592 & 5396 & 5494 & 4924 & 1366 & 3430 \\
\hline \multicolumn{11}{|l|}{ Panel B: Models with 5 lags } \\
\hline Temp. cumulative effect - Poor & $\begin{array}{c}-1.041 * * \\
(0.530)\end{array}$ & $\begin{array}{c}-2.025 * * \\
(0.907)\end{array}$ & $\begin{array}{l}-0.400 \\
(0.480)\end{array}$ & $\begin{array}{l}-0.319 \\
(0.413)\end{array}$ & $\begin{array}{l}-0.931 \\
(0.943)\end{array}$ & $\begin{array}{c}-1.067 * * \\
(0.494)\end{array}$ & $\begin{array}{c}-0.738 * * * \\
(0.269)\end{array}$ & $\begin{array}{l}-0.874 * \\
(0.522)\end{array}$ & $\begin{array}{l}-0.705 \\
(0.840)\end{array}$ & $\begin{array}{l}-1.318^{*} \\
(0.684)\end{array}$ \\
\hline Temp. cumulative effect - Rich & $\begin{array}{l}-0.191 \\
(0.546)\end{array}$ & $\begin{array}{c}0.245 \\
(0.961)\end{array}$ & $\begin{array}{l}-0.524 \\
(0.535)\end{array}$ & $\begin{array}{l}-0.475 \\
(0.480)\end{array}$ & $\begin{array}{c}0.276 \\
(0.654)\end{array}$ & $\begin{array}{l}-0.073 \\
(0.582)\end{array}$ & $\begin{array}{c}-0.022 \\
(0.517)\end{array}$ & $\begin{array}{l}-0.053 \\
(0.504)\end{array}$ & & $\begin{array}{l}-0.377 \\
(0.562)\end{array}$ \\
\hline Precip. cumulative effect - Poor & $\begin{array}{c}0.238 \\
(0.194)\end{array}$ & $\begin{array}{c}0.211 \\
(0.290)\end{array}$ & $\begin{array}{c}0.187 \\
(0.179)\end{array}$ & $\begin{array}{c}0.154 \\
(0.171)\end{array}$ & $\begin{array}{c}0.221 \\
(0.215)\end{array}$ & $\begin{array}{c}0.084 \\
(0.139)\end{array}$ & $\begin{array}{c}0.193 \\
(0.169)\end{array}$ & $\begin{array}{c}0.241 \\
(0.191)\end{array}$ & $\begin{array}{c}0.868 \\
(0.611)\end{array}$ & $\begin{array}{l}-0.003 \\
(0.141)\end{array}$ \\
\hline Precip. cumulative effect - Rich & $\begin{array}{l}-0.127 \\
(0.088)\end{array}$ & $\begin{array}{l}-0.084 \\
(0.208)\end{array}$ & $\begin{array}{l}-0.088 \\
(0.087)\end{array}$ & $\begin{array}{l}-0.048 \\
(0.073)\end{array}$ & $\begin{array}{l}-0.161 \\
(0.196)\end{array}$ & $\begin{array}{l}-0.039 \\
(0.142)\end{array}$ & $\begin{array}{l}-0.134 \\
(0.094)\end{array}$ & $\begin{array}{l}-0.129 \\
(0.089)\end{array}$ & & $\begin{array}{l}-0.121 \\
(0.089)\end{array}$ \\
\hline Observations & 4916 & 4916 & 4916 & 4916 & 2592 & 5285 & 5272 & 4916 & 1366 & 3422 \\
\hline \multicolumn{11}{|l|}{ Panel C: Models with 10 lags } \\
\hline Temp. cumulative effect - Poor & $\begin{array}{l}-0.858 \\
(0.647)\end{array}$ & $\begin{array}{l}-1.964 \\
(1.211)\end{array}$ & $\begin{array}{l}-0.166 \\
(0.630)\end{array}$ & $\begin{array}{l}-0.252 \\
(0.591)\end{array}$ & $\begin{array}{l}-0.951 \\
(1.242)\end{array}$ & $\begin{array}{l}-0.791 \\
(0.641)\end{array}$ & $\begin{array}{c}-0.768 * * \\
(0.337)\end{array}$ & $\begin{array}{l}-0.683 \\
(0.635)\end{array}$ & $\begin{array}{l}-0.803 \\
(0.994)\end{array}$ & $\begin{array}{l}-0.969 \\
(0.843)\end{array}$ \\
\hline Temp. cumulative effect - Rich & $\begin{array}{l}-0.189 \\
(0.758)\end{array}$ & $\begin{array}{c}0.582 \\
(1.414)\end{array}$ & $\begin{array}{l}-0.271 \\
(0.706)\end{array}$ & $\begin{array}{l}-0.272 \\
(0.624)\end{array}$ & $\begin{array}{c}0.198 \\
(0.913)\end{array}$ & $\begin{array}{l}-0.059 \\
(0.827)\end{array}$ & $\begin{array}{l}-0.443 \\
(0.822)\end{array}$ & $\begin{array}{l}-0.064 \\
(0.738)\end{array}$ & & $\begin{array}{l}-0.469 \\
(0.783)\end{array}$ \\
\hline Precip. cumulative effect - Poor & $\begin{array}{l}0.429 * \\
(0.227)\end{array}$ & $\begin{array}{c}0.573 \\
(0.413)\end{array}$ & $\begin{array}{c}0.323 \\
(0.215)\end{array}$ & $\begin{array}{c}0.267 \\
(0.217)\end{array}$ & $\begin{array}{l}0.455^{*} \\
(0.244)\end{array}$ & $\begin{array}{c}0.236 \\
(0.180)\end{array}$ & $\begin{array}{c}0.254 \\
(0.182)\end{array}$ & $\begin{array}{c}0.435 * * \\
(0.221)\end{array}$ & $\begin{array}{c}0.922 \\
(0.770)\end{array}$ & $\begin{array}{c}0.234 \\
(0.153)\end{array}$ \\
\hline Precip. cumulative effect - Rich & $\begin{array}{l}-0.195 \\
(0.137)\end{array}$ & $\begin{array}{l}-0.142 \\
(0.370)\end{array}$ & $\begin{array}{l}-0.109 \\
(0.133)\end{array}$ & $\begin{array}{l}-0.099 \\
(0.114)\end{array}$ & $\begin{array}{l}-0.141 \\
(0.394)\end{array}$ & $\begin{array}{l}-0.183 \\
(0.178)\end{array}$ & $\begin{array}{l}-0.070 \\
(0.134)\end{array}$ & $\begin{array}{l}-0.196 \\
(0.138)\end{array}$ & & $\begin{array}{l}-0.180 \\
(0.143)\end{array}$ \\
\hline Observations & 4906 & 4906 & 4906 & 4906 & 2590 & 5146 & 4946 & 4906 & 1366 & 3412 \\
\hline
\end{tabular}

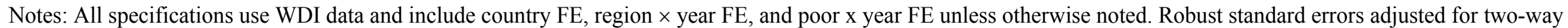

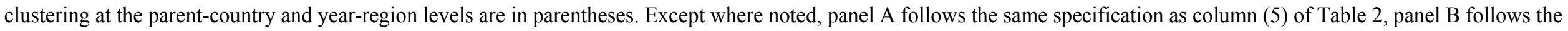

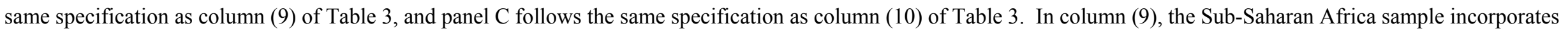
three rich countries - South Africa, Gabon, and Mauritius. 
Table 5: Components of Output Growth

Panel A: Models with no lags

\begin{tabular}{cccc} 
& \multicolumn{3}{c}{ Dependent variable is: } \\
& $(1)$ & $(2)$ & $(3)$ \\
& Growth in & Growth in & Growth in \\
& Agriculture & Industrial Value & Investment \\
& Value Added & Added & \\
Nemperature & No lags & No lags & No lags \\
Immediate effect - Poor & $-2.666^{* * *}$ & $-2.036^{* *}$ & -0.895 \\
& $(0.948)$ & $(0.878)$ & $(1.269)$ \\
Immediate effect - Rich & -0.222 & 0.514 & 0.182 \\
& $(0.650)$ & $(0.452)$ & $(0.870)$ \\
Precipitation & & & \\
Immediate effect - Poor & 0.182 & 0.238 & -0.019 \\
& $(0.135)$ & $(0.146)$ & $(0.223)$ \\
Immediate effect - Rich & 0.16 & -0.007 & $-0.419 *$ \\
& $(0.119)$ & $(0.100)$ & $(0.217)$ \\
Observations & 3835 & 3835 & 4419 \\
\hline \hline
\end{tabular}

Panel B: Models with lags

\begin{tabular}{|c|c|c|c|c|c|c|c|c|c|}
\hline \multirow{4}{*}{$\begin{array}{l} \\
\text { Temperature } \\
\text { Cumulative effect - Poor }\end{array}$} & \multicolumn{9}{|c|}{ Dependent variable is: } \\
\hline & \multicolumn{3}{|c|}{ Growth in Agriculture Value Added } & \multicolumn{3}{|c|}{ Growth in Industrial Value Added } & \multicolumn{3}{|c|}{ Growth in Investment } \\
\hline & $1 \mathrm{Lag}$ & 5 Lags & 10 Lags & $1 \mathrm{Lag}$ & 5 Lags & 10 Lags & $1 \mathrm{Lag}$ & 5 Lags & 10 Lags \\
\hline & $\begin{array}{c}-1.26 \\
(0.882)\end{array}$ & $\begin{array}{l}-1.051 \\
(1.007)\end{array}$ & $\begin{array}{c}-1.337 \\
(1.203)\end{array}$ & $\begin{array}{l}-1.835 \\
(1.123)\end{array}$ & $\begin{array}{c}-0.958 \\
(1.365)\end{array}$ & $\begin{array}{c}-2.242 \\
(1.796)\end{array}$ & $\begin{array}{c}1.17 \\
(1.287)\end{array}$ & $\begin{array}{c}0.128 \\
(1.665)\end{array}$ & $\begin{array}{c}-0.219 \\
(1.797)\end{array}$ \\
\hline Cumulative effect - Rich & $\begin{array}{c}0.328 \\
(0.678)\end{array}$ & $\begin{array}{c}0.002 \\
(0.754)\end{array}$ & $\begin{array}{c}0.236 \\
(1.203)\end{array}$ & $\begin{array}{c}0.653 \\
(0.572)\end{array}$ & $\begin{array}{c}0.111 \\
(0.734)\end{array}$ & $\begin{array}{c}0.321 \\
(1.096)\end{array}$ & $\begin{array}{c}0.598 \\
(0.894)\end{array}$ & $\begin{array}{c}-1.38 \\
(1.333)\end{array}$ & $\begin{array}{c}-1.283 \\
(1.356)\end{array}$ \\
\hline Immediate effect - Poor & $\begin{array}{c}-3.684 * * * \\
(1.389)\end{array}$ & $\begin{array}{c}-3.703 * * * \\
(1.385)\end{array}$ & $\begin{array}{c}-3.797 * * * \\
(1.416)\end{array}$ & $\begin{array}{c}-2.091 * * \\
(0.987)\end{array}$ & $\begin{array}{c}-2.334 * * \\
(1.112)\end{array}$ & $\begin{array}{c}-2.578 * * \\
(1.172)\end{array}$ & $\begin{array}{c}-2.235 \\
(1.946)\end{array}$ & $\begin{array}{l}-1.851 \\
(1.972)\end{array}$ & $\begin{array}{l}-2.229 \\
(2.025)\end{array}$ \\
\hline Immediate effect - Rich & $\begin{array}{c}-0.543 \\
(0.792)\end{array}$ & $\begin{array}{c}-0.468 \\
(0.793)\end{array}$ & $\begin{array}{c}-0.566 \\
(0.815)\end{array}$ & $\begin{array}{c}0.457 \\
(0.486)\end{array}$ & $\begin{array}{c}0.433 \\
(0.498)\end{array}$ & $\begin{array}{c}0.404 \\
(0.500)\end{array}$ & $\begin{array}{c}-0.079 \\
(1.185)\end{array}$ & $\begin{array}{c}0.19 \\
(1.199)\end{array}$ & $\begin{array}{c}0.282 \\
(1.172)\end{array}$ \\
\hline \multicolumn{10}{|l|}{ Precipitation } \\
\hline Cumulative effect - Poor & $\begin{array}{c}0.094 \\
(0.120)\end{array}$ & $\begin{array}{c}0.129 \\
(0.159)\end{array}$ & $\begin{array}{c}0.052 \\
(0.185)\end{array}$ & $\begin{array}{c}0.328 * * \\
(0.158)\end{array}$ & $\begin{array}{c}0.205 \\
(0.237)\end{array}$ & $\begin{array}{c}0.23 \\
(0.322)\end{array}$ & $\begin{array}{c}0.148 \\
(0.268)\end{array}$ & $\begin{array}{c}0.007 \\
(0.289)\end{array}$ & $\begin{array}{c}-0.283 \\
(0.349)\end{array}$ \\
\hline Cumulative effect - Rich & $\begin{array}{l}0.207^{*} \\
(0.120)\end{array}$ & $\begin{array}{c}0.394 * * * \\
(0.143)\end{array}$ & $\begin{array}{c}0.476^{* *} \\
(0.233)\end{array}$ & $\begin{array}{c}-0.071 \\
(0.135)\end{array}$ & $\begin{array}{c}-0.083 \\
(0.229)\end{array}$ & $\begin{array}{c}-0.113 \\
(0.303)\end{array}$ & $\begin{array}{c}-0.317 \\
(0.203)\end{array}$ & $\begin{array}{l}-0.017 \\
(0.336)\end{array}$ & $\begin{array}{c}-0.519 \\
(0.364)\end{array}$ \\
\hline Immediate effect - Poor & $\begin{array}{c}0.22 \\
(0.180)\end{array}$ & $\begin{array}{c}0.235 \\
(0.197)\end{array}$ & $\begin{array}{c}0.252 \\
(0.208)\end{array}$ & $\begin{array}{c}0.188 \\
(0.187)\end{array}$ & $\begin{array}{c}0.108 \\
(0.168)\end{array}$ & $\begin{array}{c}0.078 \\
(0.166)\end{array}$ & $\begin{array}{c}-0.106 \\
(0.361)\end{array}$ & $\begin{array}{c}-0.174 \\
(0.402)\end{array}$ & $\begin{array}{c}-0.19 \\
(0.405)\end{array}$ \\
\hline Immediate effect - Rich & $\begin{array}{c}0.154 \\
(0.172)\end{array}$ & $\begin{array}{c}0.153 \\
(0.184)\end{array}$ & $\begin{array}{c}0.169 \\
(0.192)\end{array}$ & $\begin{array}{c}0.012 \\
(0.124)\end{array}$ & $\begin{array}{c}0.001 \\
(0.132)\end{array}$ & $\begin{array}{c}0.002 \\
(0.137)\end{array}$ & $\begin{array}{c}-0.434 * \\
(0.262)\end{array}$ & $\begin{array}{c}-0.468 * \\
(0.282)\end{array}$ & $\begin{array}{c}-0.457 \\
(0.283)\end{array}$ \\
\hline Observations & 3835 & 3827 & 3817 & 3835 & 3827 & 3817 & 4419 & 4411 & 4401 \\
\hline
\end{tabular}

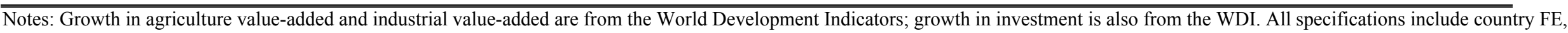

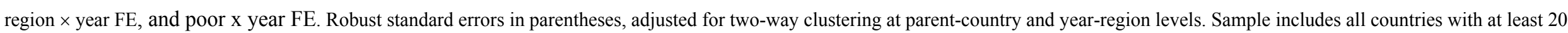
years of PWT growth observations (i.e., the same set of countries considered in the previous tables.) 
Table 6: Political economy effects

(1)

\begin{tabular}{|c|c|c|c|c|c|c|}
\hline & $\begin{array}{l}\text { Any change in } \\
\text { POLITY score }\end{array}$ & $\begin{array}{l}\text { Leader } \\
\text { transition }\end{array}$ & $\begin{array}{l}\text { Regular leader } \\
\text { transition }\end{array}$ & $\begin{array}{c}\text { Irregular leader } \\
\text { transition }\end{array}$ & $\begin{array}{l}\text { Start of conflicts } \\
\text { (conditional on } \\
\text { conflict }=0 \text { in } \mathrm{t}-1 \text { ) }\end{array}$ & $\begin{array}{l}\text { End of conflicts } \\
\text { (conditional on } \\
\text { conflict }>0 \text { in } t-1 \text { ) }\end{array}$ \\
\hline \multirow[t]{2}{*}{ Temperature } & $(0.013)$ & $(0.002)$ & 0.004 & $(0.005)$ & $(0.006)$ & 0.005 \\
\hline & $(0.009)$ & $(0.015)$ & $(0.015)$ & $(0.004)$ & $(0.006)$ & $(0.060)$ \\
\hline Temperature & $0.040 * *$ & 0.033 & $(0.017)$ & $0.050 * * *$ & 0.012 & 0.003 \\
\hline X Poor & $(0.016)$ & $(0.023)$ & $(0.017)$ & $(0.013)$ & $(0.013)$ & $(0.068)$ \\
\hline \multirow[t]{2}{*}{ Precipitation } & $(0.001)$ & 0.003 & 0.003 & 0.000 & 0.000 & 0.023 \\
\hline & $(0.003)$ & $(0.002)$ & $(0.003)$ & $(0.001)$ & $(0.001)$ & $(0.019)$ \\
\hline \multirow{2}{*}{$\begin{array}{l}\text { Precipitation } \\
\text { X Poor }\end{array}$} & $(0.008)$ & $-0.008^{*}$ & $-0.008 * *$ & 0.000 & 0.000 & $(0.031)$ \\
\hline & $(0.005)$ & $(0.004)$ & $(0.004)$ & $(0.002)$ & $(0.002)$ & $(0.020)$ \\
\hline Obs. & 5388 & 6624 & 6624 & 6624 & 5702 & 852 \\
\hline R-squared & 0.14 & 0.18 & 0.2 & 0.11 & 0.09 & 0.43 \\
\hline \\
\hline \multicolumn{7}{|l|}{$\begin{array}{l}\text { Temperature } \\
\text { effect in }\end{array}$} \\
\hline poor & $0.027^{*}$ & $0.031 *$ & -0.013 & $0.044 * * *$ & 0.007 & 0.008 \\
\hline Countries & $(0.015)$ & $(0.017)$ & $(0.010)$ & $(0.013)$ & $(0.011)$ & $(0.037)$ \\
\hline \multicolumn{7}{|l|}{$\begin{array}{l}\text { Precipitation } \\
\text { effect in }\end{array}$} \\
\hline poor & $-0.009 * *$ & -0.005 & $-0.005^{*}$ & 0.000 & 0.000 & -0.009 \\
\hline Countries & $(0.004)$ & $(0.004)$ & $(0.003)$ & $(0.002)$ & $(0.002)$ & $(0.007)$ \\
\hline
\end{tabular}

Notes: Columns (1) uses data from the POLITY IV dataset; columns (2)-(4) use data from the Archigos dataset; and columns (5)-(6) use data from the PRIO dataset. Columns (1) - (4) include country FE, region $\times$ year FE, and poor x year FE; columns (5)-(6) include country FE and year FE. Robust standard errors in parentheses, adjusted for two-way clustering at parent-country and year-region levels. Sample includes all countries with at least 20 years of WDI growth observations (i.e., the same set of countries considered in the previous tables.)

$*$ significant at $10 \%$; * significant at $5 \%$; ** significant at $1 \%$ 
Table 7: Changes in growth and temperature in the medium-run

\begin{tabular}{|c|c|c|c|c|c|c|c|c|c|c|c|}
\hline & \multicolumn{11}{|c|}{ Dependent variable: change in mean growth rate } \\
\hline & (1) & (2) & (3) & (4) & $(5)$ & $(6)$ & $(7)$ & $(8)$ & $(9)$ & $(10)$ & $(11)$ \\
\hline & \multicolumn{4}{|c|}{ Baseline Sample } & \multicolumn{4}{|c|}{ Alternative comparison years } & Africa Only & $\begin{array}{c}\text { Excluding } \\
\text { Africa }\end{array}$ & $\begin{array}{l}\text { PWT } \\
\text { data }\end{array}$ \\
\hline & \multicolumn{2}{|c|}{ OLS } & \multicolumn{2}{|c|}{ Median regression } & & & & & & & \\
\hline Change in & 0.952 & 1.325 & 0.004 & 0.440 & 0.879 & -1.365 & 1.080 & 0.190 & -1.654 & 1.318 & 1.576 \\
\hline Temperature & $(1.021)$ & $(0.980)$ & $(0.584)$ & $(0.747)$ & $(0.706)$ & $(0.942)$ & $(0.944)$ & $(0.891)$ & $(2.250)$ & $(1.004)$ & $(1.135)$ \\
\hline Change in Tem & $-2.886 * *$ & $-3.010 * *$ & $-2.261 * *$ & $-2.540 * *$ & $-2.310^{*}$ & 0.490 & $-3.346^{* *}$ & -1.848 & & $-2.980 * *$ & $-3.917 * *$ \\
\hline X Poor Country & $(1.420)$ & $(1.456)$ & $(0.932)$ & $(1.177)$ & $(1.195)$ & $(1.065)$ & $(1.680)$ & $(1.546)$ & & $(1.435)$ & $(1.532)$ \\
\hline Change in & -0.070 & -0.047 & 0.028 & 0.038 & -0.045 & -0.299 & -0.058 & -0.008 & 0.034 & -0.020 & 0.025 \\
\hline Precipitation & $(0.097)$ & $(0.123)$ & $(0.113)$ & $(0.111)$ & $(0.111)$ & $(0.220)$ & $(0.220)$ & $(0.107)$ & $(0.565)$ & $(0.121)$ & $(0.111)$ \\
\hline Change in Pre & 0.060 & 0.050 & 0.120 & 0.315 & 0.100 & 0.535 & 0.423 & 0.149 & & 0.009 & 0.010 \\
\hline X Poor Country & $(0.191)$ & $(0.214)$ & $(0.182)$ & $(0.208)$ & $(0.226)$ & $(0.325)$ & $(0.435)$ & $(0.234)$ & & $(0.212)$ & $(0.238)$ \\
\hline Region FE & No & Yes & No & Yes & Yes & Yes & Yes & Yes & No & Yes & Yes \\
\hline $\begin{array}{l}\text { Poor Country } \\
\text { Dummy }\end{array}$ & Yes & Yes & Yes & Yes & Yes & Yes & Yes & Yes & No & Yes & Yes \\
\hline Early Period & 1970-1985 & 1970-1985 & 1970-1985 & 1970-1985 & $1970-1987$ & $1961-1970$ & 1971-1980 & $\begin{array}{c}1981- \\
1990\end{array}$ & $1970-1985$ & $1970-1985$ & $1970-1985$ \\
\hline Late Period & 1986-2000 & $1986-2000$ & $1986-2000$ & $1986-2000$ & $1988-2003$ & 1991-2000 & 1991-2000 & $\begin{array}{l}1991- \\
2000\end{array}$ & $1986-2000$ & $1986-2000$ & $1986-2000$ \\
\hline Observations & 125 & 125 & 125 & 125 & 125 & 101 & 112 & 124 & 38 & 87 & 120 \\
\hline R-squared & 0.04 & 0.11 & & & 0.09 & 0.26 & 0.18 & 0.17 & 0.06 & 0.19 & 0.12 \\
\hline Within R-squared & 0.03 & 0.04 & & & 0.03 & 0.05 & 0.08 & 0.02 & 0.04 & 0.04 & 0.06 \\
\hline Tem effect on & $-1.934^{*}$ & -1.684 & $-2.257 * * *$ & $-2.100 * *$ & -1.431 & -0.875 & -2.266 & -1.658 & -1.654 & -1.661 & $-2.341 * *$ \\
\hline poor countries & $(0.986)$ & $(1.088)$ & $(0.726)$ & $(0.919)$ & $(0.982)$ & $(0.688)$ & (1.399) & $(1.279)$ & $(2.250)$ & $(1.047)$ & $(1.029)$ \\
\hline Pre effect on poor & -0.010 & 0.003 & 0.148 & $0.354 * *$ & 0.055 & 0.236 & 0.365 & 0.141 & 0.034 & -0.012 & 0.035 \\
\hline Countries & $(0.164)$ & $(0.167)$ & $(0.143)$ & $(0.175)$ & $(0.187)$ & $(0.232)$ & $(0.396)$ & $(0.209)$ & $(0.565)$ & $(0.153)$ & $(0.211)$ \\
\hline
\end{tabular}

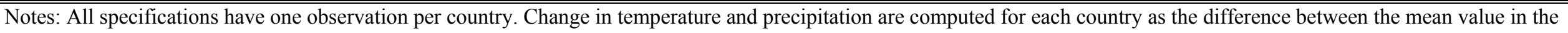

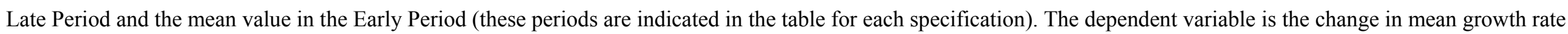

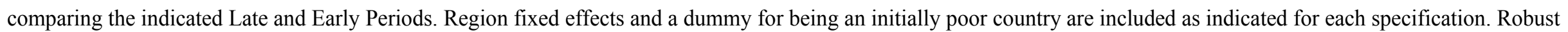

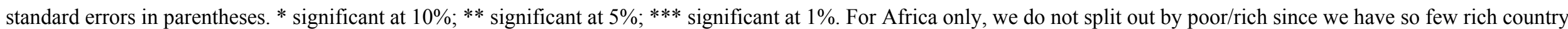
observations in Sub-Saharan Africa. 
Figure 1: Changes and variability in temperature and precipitation
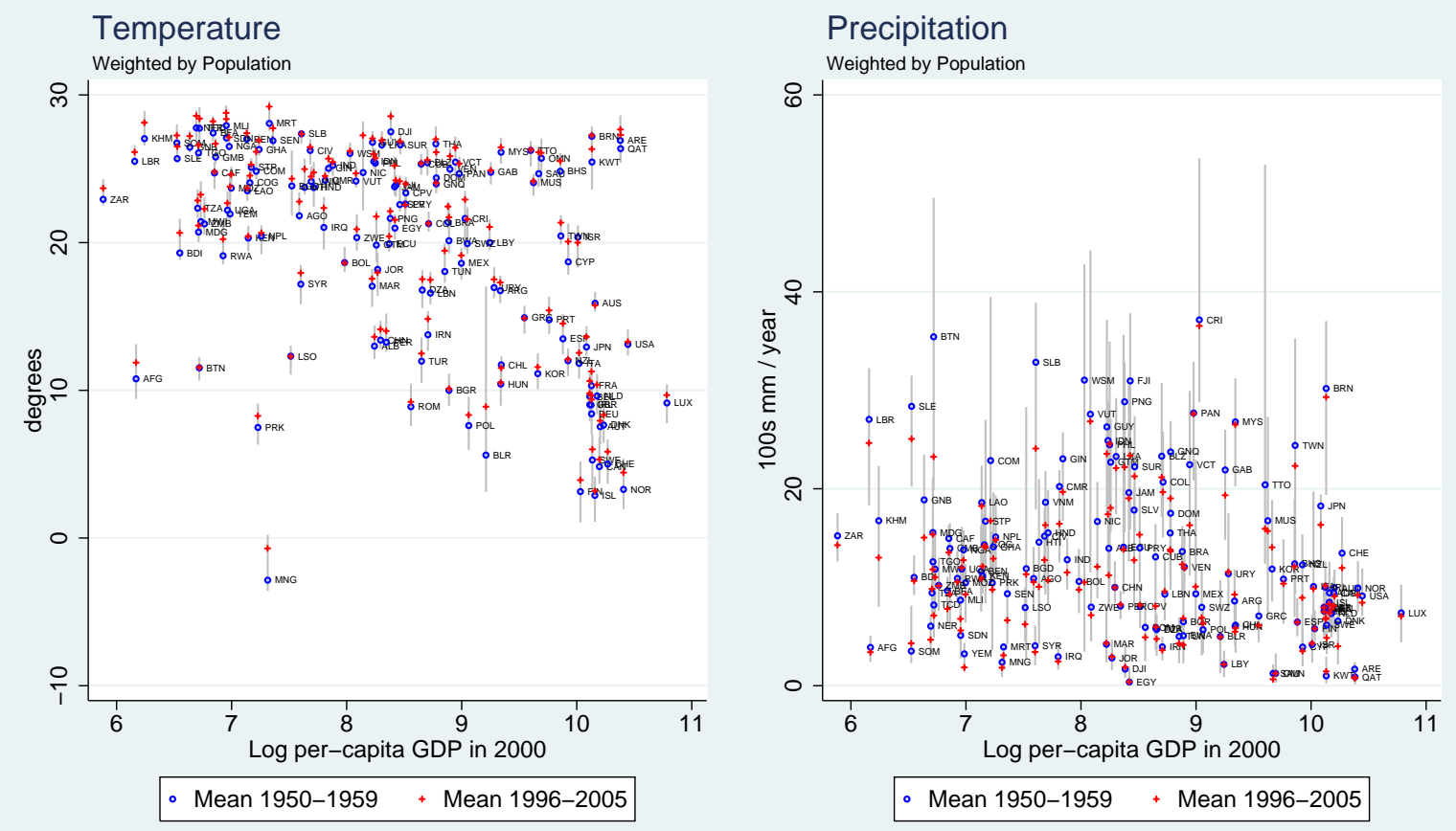

Notes: These graphs present data on each country's temperature (left graph) and precipitation (right graph), potted against per-capita PPP GDP from the Penn World Tables in the year 2000. For each country, the circle symbols represent the mean level of temperature / precipitation in the first decade of our sample (1950-1959), the plus symbols represent the mean level of temperature / precipitation in the last decade of our sample (1996-2005), and the gray lines indicate the range of annual temperature / precipitation levels we observe for that country during our sample period. Country averages are calculated using population weights, as discussed in the text. 
Figure 2: Changes in growth and temperature in the medium-run

A. Poor countries

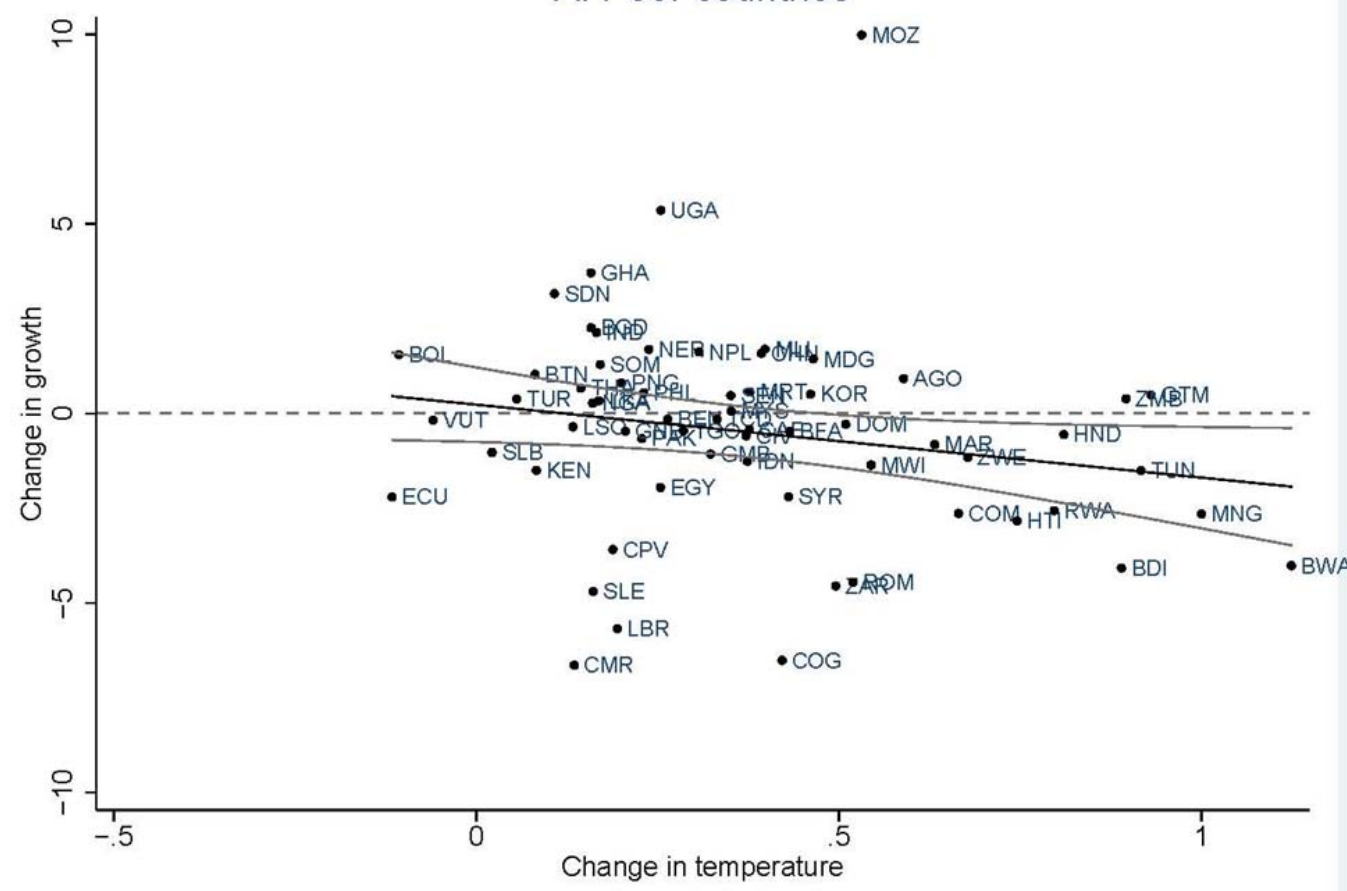

B. Rich countries

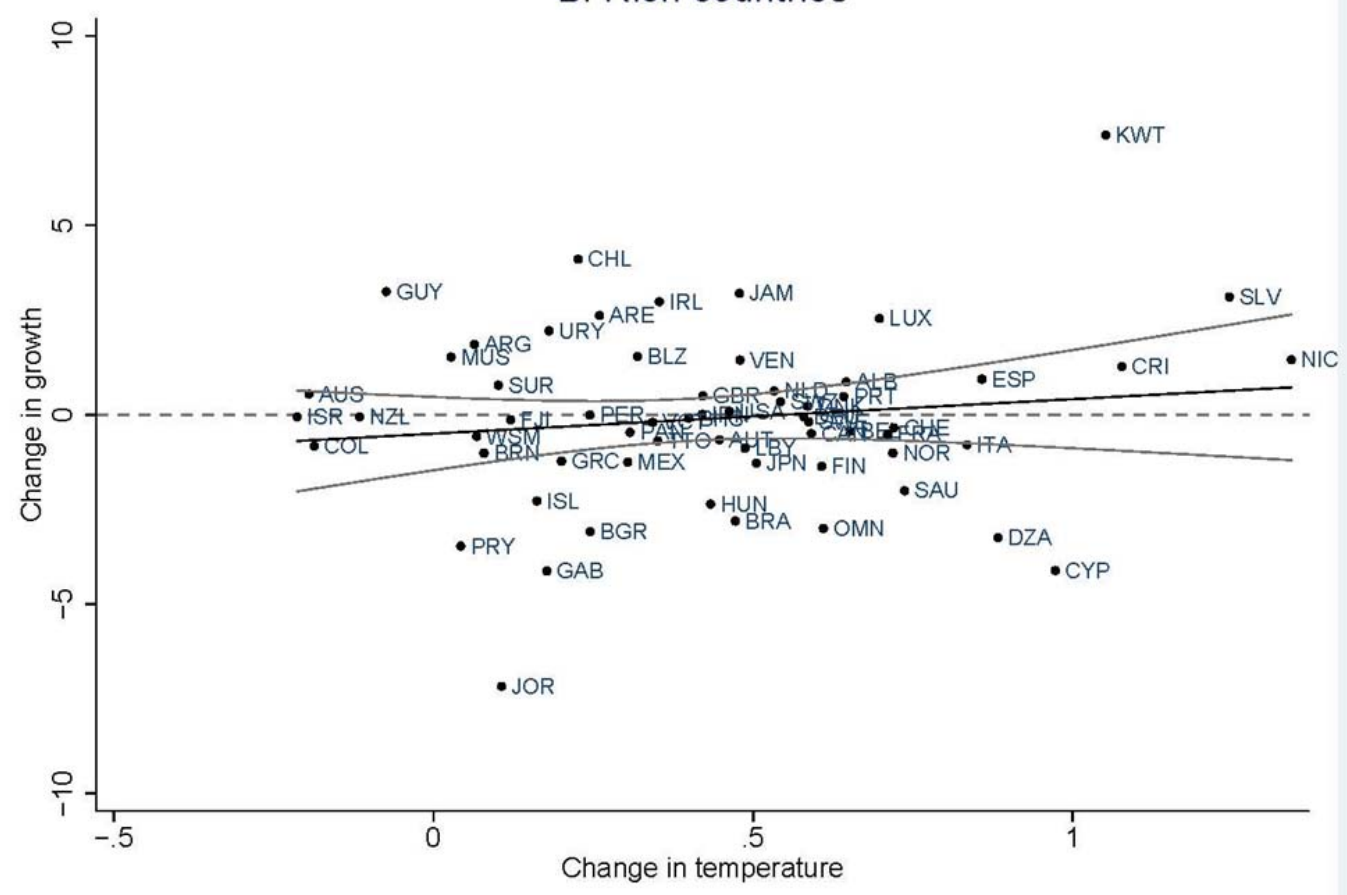

Notes: Panels A and B plot the change in average annual growth against the change in average annual temperature between the periods 1970-1985 and 1986-2000, for rich and poor countries respectively. 